\title{
Review on metal nanoparticles as nanocarriers: current challenges and perspectives in drug delivery systems
}

\author{
V. Chandrakala ${ }^{1} \cdot$ Valmiki Aruna $^{1} \cdot$ Gangadhara Angajala $^{1}[$
}

Received: 23 June 2021 / Accepted: 9 December 2021 / Published online: 4 January 2022

(c) Qatar University and Springer Nature Switzerland AG 2021

\begin{abstract}
Over the past few years, nanotechnology has been attracting considerable research attention because of their outstanding mechanical, electromagnetic and optical properties. Nanotechnology is an interdisciplinary field comprising nanomaterials, nanoelectronics, and nanobiotechnology, as three areas which extensively overlap. The application of metal nanoparticles (MNPs) has drawn much attention offering significant advances, especially in the field of medicine by increasing the therapeutic index of drugs through site specificity preventing multidrug resistance and delivering therapeutic agents efficiently. Apart from drug delivery, some other applications of MNPs in medicine are also well known such as in vivo and in vitro diagnostics and production of enhanced biocompatible materials and nutraceuticals. The use of metallic nanoparticles for drug delivery systems has significant advantages, such as increased stability and half-life of drug carrier in circulation, required biodistribution, and passive or active targeting into the required target site. Green synthesis of MNPs is an emerging area in the field of bionanotechnology and provides economic and environmental benefits as an alternative to chemical and physical methods. Therefore, this review aims to provide up-to-date insights on the current challenges and perspectives of MNPs in drug delivery systems. The present review was mainly focused on the greener methods of metallic nanocarrier preparations and its surface modifications, applications of different MNPs like silver, gold, platinum, palladium, copper, zinc oxide, metal sulfide and nanometal organic frameworks in drug delivery systems.
\end{abstract}

Keywords Nanocarriers $\cdot$ Metallic nanoparticles $\cdot$ Drug delivery $\cdot$ Drug carriers

\section{Introduction}

Nanotechnology is a science that deals with the preparation of nanosize particles ranging from 1 to $100 \mathrm{~nm}$ employing diverse synthetic strategies, particle structure and size modification [1]. The technological leap of controlling materials at nanoscale provides for a big revolution in medical and healthcare treatments and therapies. The use of nanoparticles in different fields like molecular biology, physics, organic and inorganic chemistry, medicine, and material science is unexpectedly augmented nowadays [2,3]. It is reported that moving from bulk materials into nanosize will change their physicochemical properties, which can be utilized in diverse biomedical applications. Nanoparticles are extremely

Gangadhara Angajala

gangadharaangajala@gmail.com

1 Department of Chemistry, Kalasalingam Academy of Research and Education, Anand Nagar, Krishnan Koil 626126, Tamil Nadu, India attractive for several biomedical applications mainly due to its high surface to volume ratio with the capability to interact with the molecular or cellular process and the possibility to influence their functions [4]. Drug delivery systems (DDS) are one of the greatest promising applications of human health care and represent an eternally progressing field for medical sciences. In spite of vast development in the field of DDS, still it is a crucial challenge for formulation scientists to develop an appropriate carrier that is efficient for drug delivery to the body with maximum benefit to risk ratio [5]. The development of drug-delivery systems has been an active field of multidisciplinary research for more than 20 years and has led to successful improvement of treatments for different pathologies [6, 7]. Nanoscale drug delivery systems are an important route to reduce the side effects and improve the treatment efficacy of chemotherapy drugs. The use of nanostructured materials provides incomparable liberty to customize the intrinsic properties of the drug in DDS such as drug release characteristics, dissolution, solubility, bioavailability, $t_{1 / 2}$, and immunogenicity

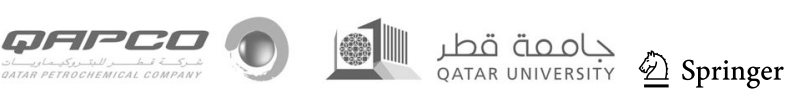


[8]. Another important feature of nanostructured materials (NSM) is its comparable size of the cell organelles in the human cell and this property makes them a potential candidate for DDS as the variety of physiological processes take place at nanoscales (Fig. 1). Formation of stable interactions with ligands, variability in size and shape, high carrier capacity and convenience of binding of both hydrophilic and hydrophobic substances make nanoparticles favorable platforms for the target-specific and controlled delivery of micro and macromolecules in disease therapy [9]. The side effects and poor bioavailability associated with existing drugs make NSM as an effective drug delivery system. It means that the delivery of therapeutic agent directly to the tumor cells is a critical challenge. Some conventional chemotherapy drugs used to treat cancer can increase the risk of heart problems, which can also occur with radiation therapy which includes myocardial infarction, heart attack, stroke and blood clot [10]. By using metal nanoparticles, drug delivery system can minimize these types of side effects because they directly target the affected organ and thereby reduces the side effects.

In the field of nanobiotechnology, synthesis of MNPs is considered as a progressive area attracting scientific research with significant importance on imaging and drug delivery $[11,12]$. MNPs are of great interest because of its optical properties such as surface plasmon resonance (SPR) with the ability to control optical field which makes them potential candidates for biomedical applications. The small size of MNPs facilitates them to infiltrate through the biological or physiological membrane that is usually impermeable to other macromolecules $[13,14]$. To alter the pharmacokinetics properties, the surface of the MNPs can be tuned accordingly. For example the circulation time of the MNPs within the body can be enhanced by reducing the non-specific uptake by mononuclear phagocyte system through coating the surface of MNPs with polyethylene glycol (PEG). Over the past years, there is a rapid improvement in the utilization of MNPs as drug delivery carriers for the treatment of tumor cells [15]. Applying radiation or removing tumor surgically is the most common treatment for cancer. Utilizing therapeutic agents is non-invasive process and produce promising results when compared with other treatments, still they have some problem in practice: the selectivity of the treatments cannot reach the target site, tumor cells cannot be killed completely and the side effects cannot be controlled [16, 17]. To overcome these problems, the MNPs are selected to synthesize smart drug delivery systems to make the agents attack directly to the target site $[18,19]$. To synthesize such type of drug delivery systems, we need to investigate the tumor and select materials for responding tumoral signal and thereby releasing drug to the target site. The growth of tumor tissues is completely different from normal healthy tissues, in addition to these, they have some biochemical differences and pathological differences; it provides chances for drug delivery system to attack the tumor selectively [20, 21]. Conjugation of targeting ligands such as antibodies, peptides or sequence of nucleic acid to target tissue or specific disease organ is mainly associated with surface chemistry of MNPs [22, 23]. Functionalized MNPs deliver the therapeutic drugs
Fig. 1 The size, shape, material, and surface of the nanoparticles

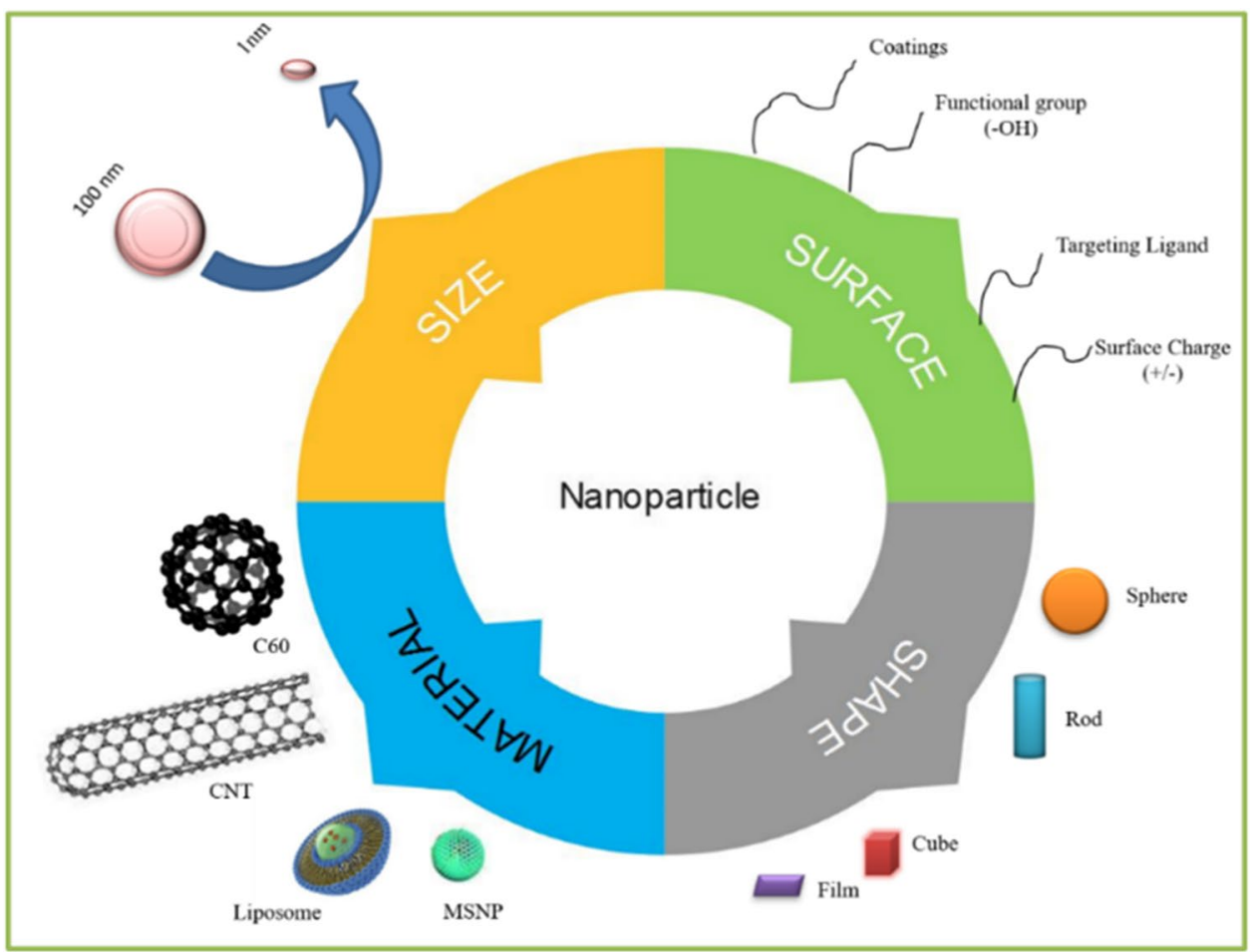


effectively by substantially increasing drug payload to the site of action into specific cells with minimal adverse effects, thereby diagnosis and treatment occur at the cellular level $[24,25]$. By considering the effective advantages of MNPs due to their large surface area, tunable hole size, high pore volume and informal surface variation, this review explores the current challenges and perspectives of various metalbased nanomaterials for their potential applications in drug delivery systems especially in the treatment of cancer, diabetes, inflammation and in anti-viral therapy.

\section{Methods of synthesizing MNPs}

The synthesis of MNPs majorly involves two different approaches named as top-down approach or dispersion method and bottom-up approach or condensation method [26]. In top-down approach, the nanoparticles are formed by size reduction method where bulk materials are broken down into small materials. This can be accomplished with the use of ultrasonic generators of greater intensity operating at frequencies around 1,200,000 rpm [27]. Another dispersion method includes the generation of an electric arc within the liquid. Metal is dispersed as vapor from the electrode due to the intense heat produced from the electric arc which condensed further to form MNPs [28].
In the bottom-up assembly, nanostructures are fabricated atom by atom or particle by particle to build up nanostructure. This can be attained by a high degree of supersaturation followed by nuclei growth [29, 30]. By considering these two approaches, various scientists have reported a variety of chemical and physical methods for production of MNPs, for instance, chemical reduction [31], microemulsion [32, 33], thermal decomposition [34, 35], sonochemical [36, 37], polyol method [38, 39], microwave-assisted method [40, 41], laser ablation [42], sputtering deposition [43], lithography [44], pulsed electrochemical etching [45], vapor deposition [46] and sol-gel [47] (Fig. 2). In chemical methods, the harsh chemical additives are added to prepare the MNPs. For example, dimethyl formamide, hydrazine, and sodium borohydride are used as reducing agents and capping agents. Moreover, this method needs to be maintained under some physical conditions like high temperature and vacuum and also these methods need to face some environmental issues because of using toxic chemicals and the waste byproducts are discharged into soil or rivers which will affect the microorganisms, plants and human health [48]. So the researchers aim to minimize the hazards by synthesizing nanomaterials via greener methods by using plant parts (root, fruit, leaves, stem and flowers), and this method was considered as ecofriendly, simple, fast, and stable method.
Fig. 2 A Schematic representation of top-down and bottom-up approaches. B Various methods involved in the synthesis of nanoparticles
A

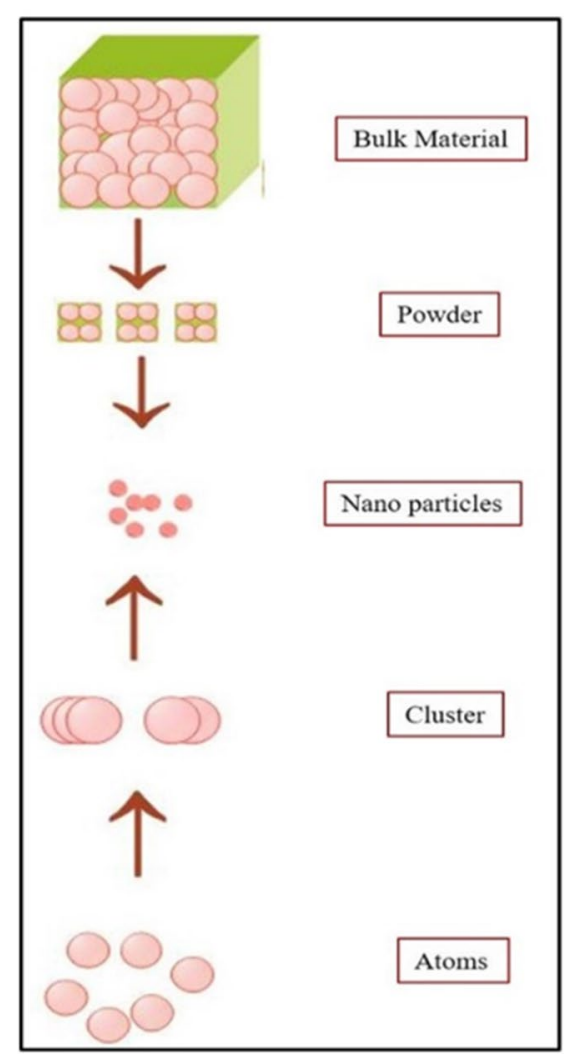

B

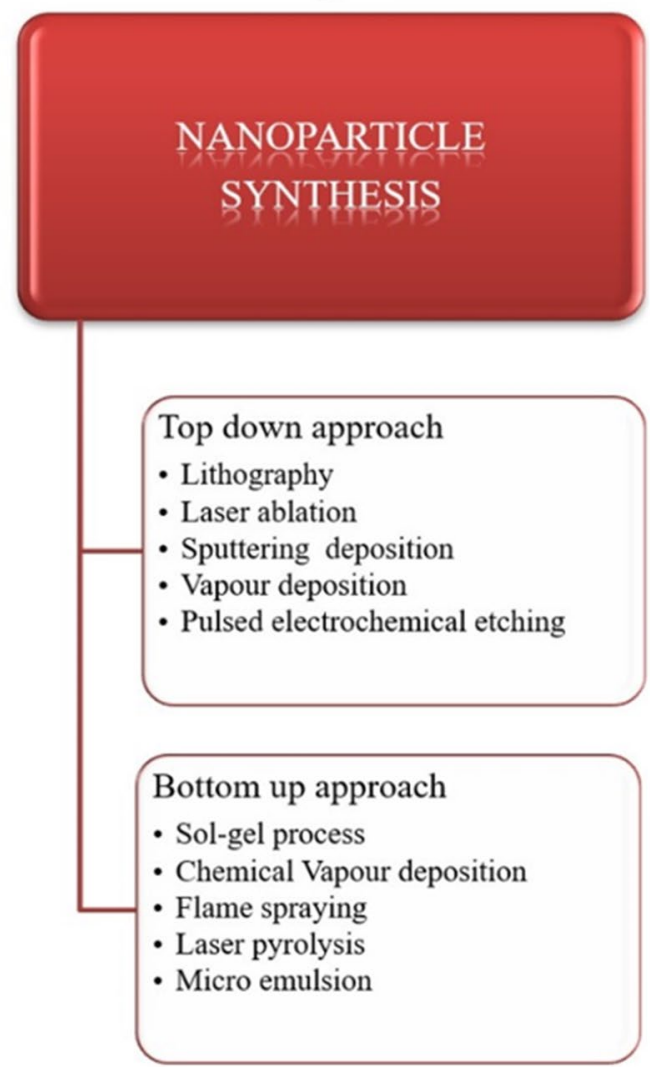


When the synthesis of MNPs was carried out by the green chemistry principle, the produced particle has more compatibility and also the greener synthesis of nanoparticles protects the environment from toxic effects [49-51]. In phytonanotechnology, the NP synthesis was carried out by using water as a solvent and this technique was non-toxic and the process was completed in a single step [52,53]. The plant extract contains proteins, amino acids, vitamins as well as secondary metabolites which act as reducing agent, capping agent, and stabilizing agent during metal NP synthesis. By using this greener approach, hazards can be minimized compared to chemical synthesis. The reference guide for the researchers, scientists and the chemists are the 12 principles of Green Chemistry to develop the low toxic nanomaterials. The greener way of synthesizing nanoparticles, mainly used in the field of nanomedicine and nanodrug delivery systems. In ancient time, humans widely used these plant-based products as medicine for several diseases. Now nearly $25 \%$ of medicines are derived from natural resources [54]. The plant-based natural compounds are basis for the invention of novel drugs [55] and they have outstanding characteristics like chemical diversity, biological property and very less hazards. Natural compounds are proved to be effective for the treatment of several diseases, in addition they have many advantages like low cost, lower side effect and less toxicity [56-58].

\section{Metallic nanoparticles in drug delivery}

In the field of nanotechnology, metallic nanoparticles have shown the number of properties, and it has unlocked many new pathways in nanotechnology especially in targeted drug delivery systems (Fig. 3) [59]. MNPs are extensively utilized as drug delivery carriers for various therapeutic agents (antibodies, nucleic acids, chemotherapeutic drugs, peptides, etc.). Most of the MNPs like silver, gold, palladium, titanium, zinc, and copper nanoparticles possess enhanced tunable optical properties. Moreover, their surface can be easily functionalized to conjugate targeting agents and active biomolecules through $\mathrm{H}$-bonding, covalent bonding and electrostatic interactions. In addition to this, multiple drugs can be easily loaded to achieve higher therapeutic efficacy [60]. MNPs are attained from their capability to increase the aqueous solubility of hydrophobic drug compound, enhanced circulation time of drugs in the blood and repress or eliminate fast renal drug excretion. Multifunctional nanoparticles have greater ability than conventional nanoparticles, to perform several goals synergistically such as co-delivery of multiple bioactive(s) with imaging agents, target-specific delivery through surface ligand decoration and simultaneously attainment of cancer therapeutics as well as diagnostics (Fig. 4) [61-63]. In drug delivery, there are

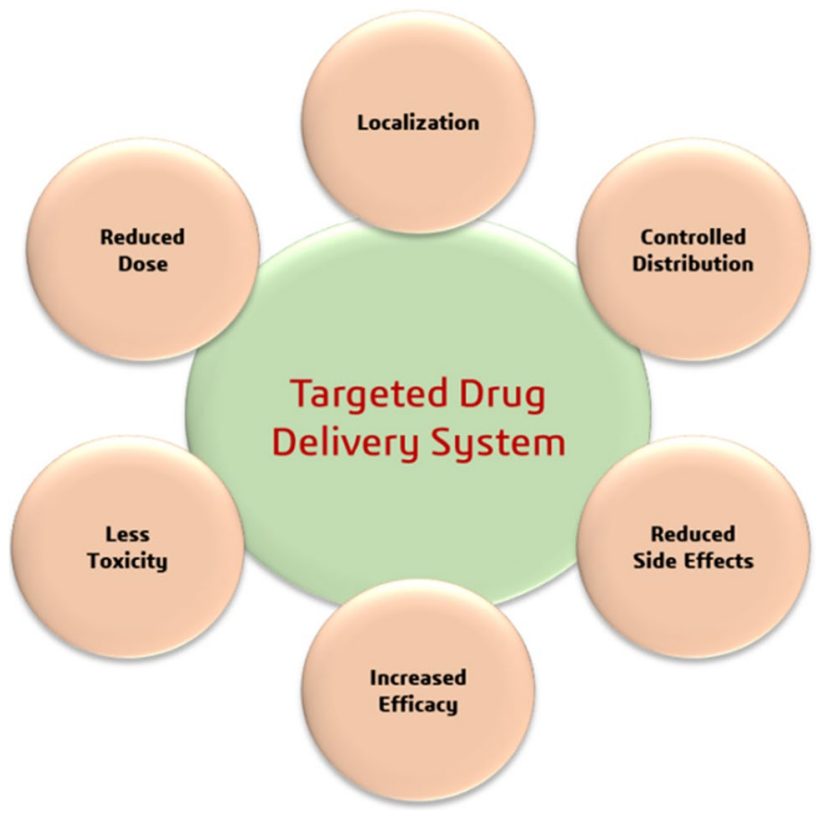

Fig. 3 Advantages of targeted drug delivery system

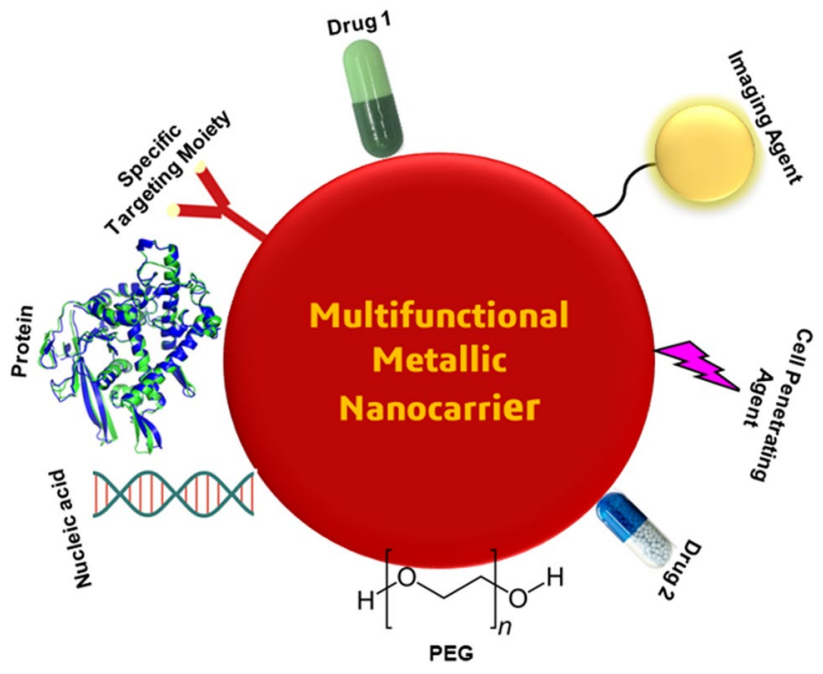

Fig. 4 Multifunctional MNP-based delivery systems for targeting, delivery, and imaging

three main goals: targeting therapeutic agent to the site of action, minimizing adverse effects of the drug to the healthy tissues or organs and controlling release of drug to avoid the classical overdosing/underdosing cycle [64]. MNPs provided a model to achieve these goals. Hence, the coating of MNP surface has been optimized to control the drug loading, drug delivery, and drug release in the target area [65]. Surface coating aim, in addition to improve biocompatibility and reduce side effects, is endowing MNPs with functional groups to be more suitable for drug combination. Efficient 
drug delivery through MNPs depends on two important factors: (i) design of MNPs for slow and sustained release of drug and (ii) ability of MNPs to distribute the therapeutic drugs to the target areas, without disturbing the other normal cells [66, 67]. By using active and passive targeting, these factors could be achieved easily. Passive targeting is possible due to the exclusive changes in the cancer vasculature. Owing to the fast growth of tumors, blood vessels and junctions are not shaped appropriately and can be leaky and lose. Due to the unique size of MNPs, they are able to travel through these loose junctions resulting in better accumulation at the tumor site and over time is primarily utilized for cancer therapeutics [68]. On the other side, in active targeting strategy, MNPs are conjugated with various active ligands that bind with specific cell surface receptors and ultimately lead to take the load to the desired site and release the drug [69].

MNPs are explored in early and clinical studies for detection, diagnosis and treatment of several diseases. MNPs have received widespread attention based on their unique material and size-dependent physicochemical property which are impossible with organic NPs [70, 71]. FDA-approved metal nanoparticle-based nanomedicines in clinical use have been shown to enhance the bioavailability and efficacy of drug delivery systems, while at the same time reducing side effects due to their properties like improved targeted delivery to active cellular uptake. By adjusting their sizes and shapes, surface chemistry and doping techniques, the designed MNPs can decompose rapidly under specific physiological conditions and are thereby easily absorbed by various metabolic pathways without affecting the healthy tissues [72]. For example, MNPs approved for cancer therapy by FDA or EMA and clinical trials are given in Table. 1.

\subsection{Characteristic properties of MNPs}

Metallic nanoparticles generally possess large surface energies which is one of the most important quantities in understanding the thermodynamics of particles. The increase in surface area to volume ratio leads to an increase in dominance behavior of the atoms at the surface rather than the interior of the particle which subsequently results in an increase in overall surface energy [73]. By using various approaches such as molecular dynamics simulations, ab initio calculations and classical thermodynamic calculations, the surface energy of the metallic nanoparticle can be determined [74]. The high surface area of MNPs provides more possible reactive sites with high surface energy which makes them ideal candidates in drug delivery systems $[75,76]$.

Table 1 Metal nanoparticles for cancer therapy approved by FDA or EMA and clinical trials

\begin{tabular}{|c|c|c|c|}
\hline Nanomaterial & Sponsor/company name & Indication/application & Clinical trial identifier \\
\hline Iron oxide & $\begin{array}{l}\text { Iron-based inorganic nanoparticles } \\
\text { Magnablate I (University College } \\
\text { London) }\end{array}$ & Prostate cancer & NCT02033447 (Ph 0) \\
\hline Magnetic iron oxide NPs & $\begin{array}{l}\text { MagProbeTM (University of New } \\
\text { Mexico) }\end{array}$ & Detection of leukemia & NCT01411904 \\
\hline $\begin{array}{l}\text { Gold nanoparticle with iron oxide } \\
\text { silica cell }\end{array}$ & NANOM (Ural Medical University) & $\begin{array}{l}\text { Plasmonic photothermal and } \\
\text { stem cell therapy of athero- } \\
\text { sclerosis }\end{array}$ & $\begin{array}{l}\text { NCT01270139 (not applicable), } \\
\text { NCT01436123 (Ph I) }\end{array}$ \\
\hline Spherical gold nanoparticle & NU-0129 (Northwestern University) & $\begin{array}{l}\text { Recurrent glioblastoma or glio- } \\
\text { sarcoma undergoing surgery }\end{array}$ & NCT03020017 (Ph 0) \\
\hline Silver nanoparticle gel & $\begin{array}{l}\text { SilvaSorb (Madigan Army Medical } \\
\text { Center) }\end{array}$ & Anti-bacterial & NCT00659204 (Ph III) \\
\hline Nanocrystalline silver & Acticoat & Pemphigus; pemphigoid & NCT02365675 (not applicable) \\
\hline $\begin{array}{l}\text { Adhesive doped with } \mathrm{Zn} \text { oxide }+\mathrm{Cu} \\
\text { nanoparticles in a }(5 \% / 0.2 \% \text { con- } \\
\text { centration) }\end{array}$ & $\begin{array}{l}\mathrm{Cu} / \mathrm{Zn} \text { nanoparticles (University of } \\
\text { Chile) }\end{array}$ & Dental varies & NCT03635138 (not applicable) \\
\hline Zinc oxide nanoparticles & Zinc oxide nanoparticles & Foot dermatoses; dental caries & $\begin{array}{l}\text { NCT04000386 (not applicable), } \\
\text { NCT03478150 (not applica- } \\
\text { ble) }\end{array}$ \\
\hline Titanium dioxide nanoparticles & Cairo University & Denture stomatitis & NCT02950584 (Ph I) \\
\hline $\begin{array}{l}\text { Mixture of gold and silver nanopar- } \\
\text { ticles }\end{array}$ & NanoCare Gold & Caries class II & NCT03669224 (not applicable) \\
\hline Hafnium oxide nanoparticle & Nanobiotix & Prostate adenocarcinoma & NCT02805894 \\
\hline $\begin{array}{l}\text { Silver nanoparticle/calcium hydrox- } \\
\text { ide }\end{array}$ & Cairo University & Postoperative pain & $\begin{array}{r}\text { NCT03692286 (Ph IV), } \\
\text { NCT04213716 (Ph II) }\end{array}$ \\
\hline
\end{tabular}




\subsection{Surface modification of MNPs}

Surface modification is a rapidly growing area of focus in the fields of nanoscience and technology, along with the design and development of nanomaterials [77]. Surface modification is necessary to stabilize a nanoparticle and prevent agglomeration. It is also essential to improve the properties of MNPs in terms of biocompatibility, wettability, adhesion and toxicity up to sufficient extent prior to their practical application in drug delivery systems [78]. The surface modification of noble metals is typically carried out by adherence, mainly with a thiol group, disulfide ligands, amines, nitriles, carboxylic acids, and phosphines. The development and the utilization of organosulphur in the surface modification was mainly attributed to its chemical feasibility in the formation of strong covalent bond with noble metals such as $\mathrm{Ag}, \mathrm{Au}, \mathrm{Cu}, \mathrm{Pt}, \mathrm{Hg}$, and $\mathrm{Fe}$ [79-81]. The crucial factor that enables the strong coordinate bond between the metal surface organo-sulfur is the higher affinity of sulfur to metal surfaces, thus making the organo-sulfur compounds readily absorbable. Surface modification of nanoparticles with long-chain polymers such as polyethylene glycol (PEG) was shown to minimize non-specific protein absorption onto the nanoparticle surface. Due to its intrinsic physicochemical properties, PEG is a favorable polymer for therapeutic nanoparticles, which decreases their phagocytic uptake and reduces their accumulation in non-target organs [82].

\section{Greener approach in the synthesis of MNPs}

Green chemistry for sustainable development has been universally studied extensively for the past 15 years [83]. The three important conditions for the synthesis of nanomaterials are the selection of environment-friendly solvent, a good reducing agent and a good stabilizing agent. Generally, the chemical methods used are too costly and incorporate the use of hazardous and toxic chemicals responsible for many risks to the environment [4], but the biosynthetic way is considered to be a safe and environmental-friendly green approach to synthesize nanoparticles for biomedical applications. The researchers from throughout the world is continuously involved in developing eco-friendly methods to produce products that are environmentally friendly and non-toxic, also highly effective, via the implementation of green nanotechnology $[84,85]$. In biology and medicine field, the used nanoparticles should have the ability of less toxicity or absence of toxicity, high compatibility and biodegradability [86]. Metal nanoparticles have different target organs and reaction response mechanisms and they have the ability to penetrate easily to the body through the skin and overcome the biological barriers, bind to nucleic acids and proteins, are embedded in cell membranes, penetrate into cell nucleus and alter their functions, and express more biological activity due to their smaller size and large surface area $[87,88]$. In spite of tremendous advantages of greener methods over other chemical methods in nanoparticle synthesis, these greener approaches also associated some minor disadvantages. The plant extracts cannot be manipulated by optimizing synthesis as a choice of nanoparticles through genetic engineering. In order to increase the productivity as a future approach, researchers are involved in the genetic modification of plants with improved metal tolerance and accumulation capacities.

\subsection{Synthesis of MNPs from biological source}

The bio-mediated synthesis using microbes (Table 2) and plants (Table 3 ) has grown as a favorable substitute to traditional methods of nanoparticle synthesis [89]. Microorganisms and plants provide potential nanofactories for low cost and eco-friendly synthesis of various metallic nanoparticles such as silver, gold, palladium, copper, and metal oxides (Fig. 5).

\subsubsection{From bacteria and actinomycetes}

Single bacteria have the ability of converting toxic metal ions into non-toxic NPs [90]. It is a promising source of synthesizing NPs because of its utilizing low energy and process controllability [91]. For example, the silver nanoparticles were synthesized from the source of Streptacidiphilus durhamensis HGG16n and it had a size range of 8-48 nm [92]; similarly Bacillus endophyticus [93] and Deinococcus radiodurans [94] are capable of producing silver nanoparticles with different shapes and sizes. Bacteria have the ability to reduce metallic ions into nanoparticles and are one of the most suitable applicants for nanoparticle synthesis because of their ease of handling. Silver nanoparticles (AgNP) synthesized by using the strain of Pseudomonas stutzeri AG259 with the size range of less than $200 \mathrm{~nm}$ by using NADH-dependant reductase enzyme that supplies electrons and itself oxidises to $\mathrm{NAD}^{+}$[95]. The transfer of electrons from NADH shows the bio reduction of silver ions into silver nanoparticles. In 2012, Srivastava et al. reported that Pseudomonas aeruginosa has the ability to synthesize different nanoparticles intracellularly for example Pd, $\mathrm{Ag}$, $\mathrm{Rh}, \mathrm{Ni}, \mathrm{Fe}, \mathrm{Co}, \mathrm{Pt}$. and Li nanoparticles [96].

Nowadays, researchers are moving towards the synthesis and development of various nanoparticles such as palladium, platinum, and tellurium. For example, Ahmed et al. reported synthesis of ultra-small palladium and platinum nanoparticles by Shewanella loihica PV-4 within the size range of 2-7 nm [97]. Srinath et al. reported the synthesis of AgNPs using Bacillus subtilis [98] extracted from gold mine have 
Table 2 Microbe-mediated nanoparticles

\begin{tabular}{|c|c|c|c|c|c|}
\hline Species & Type of microorganism & Mode & Metal & Size $(\mathrm{nm})$ & Reference \\
\hline Candida albicans & Fungi & Extracellular & $\begin{array}{l}\mathrm{Ag} \\
\mathrm{Au}\end{array}$ & $\begin{array}{l}60-80 \\
20-40\end{array}$ & $\begin{array}{l}{[115]} \\
{[116]}\end{array}$ \\
\hline Fusarium oxysporum & Fungi & Extracellular & $\begin{array}{l}\mathrm{Au} \\
\mathrm{CdS} \\
\mathrm{Zr}\end{array}$ & $\begin{array}{l}20-40 \\
5-20 \\
3-11\end{array}$ & $\begin{array}{l}{[117]} \\
{[118]} \\
{[119]}\end{array}$ \\
\hline Rhodopseudomonas capsulata & Bacteria & Extracellular & $\mathrm{Au}$ & $10-20$ & [120] \\
\hline Vibrio alginolyticus & Bacteria & $\begin{array}{l}\text { Intra cellular and } \\
\text { Extracellular }\end{array}$ & $\mathrm{Ag}$ & $50-100$ & {$[121]$} \\
\hline Pseudomonas stutzeri AG259 & Bacteria & Extracellular & $\mathrm{Ag}$ & 200 & [95] \\
\hline Pseudomonas aeruginosa & Bacteria & Intracellualar & $\begin{array}{r}\mathrm{Pd}, \mathrm{Ag}, \mathrm{Rh}, \mathrm{Ni} \\
\mathrm{Fe}, \mathrm{Co}, \mathrm{Pt}, \mathrm{Li}\end{array}$ & - & [96] \\
\hline Shewanella loihica PV-4 & Bacteria & Extracellular & $\mathrm{Pd}, \mathrm{Pt}$ & $2-7$ & [97] \\
\hline actinobacteria Rhodococcus NCIM 2891 & Actinomycetes & Extracellular & $\mathrm{Ag}$ & 10 & [101] \\
\hline actinobacteria, Streptacidiphilus durhamensis & Actinomycetes & Extracellular & $\mathrm{Ag}$ & $8-48$ & [102] \\
\hline $\begin{array}{l}\text { Streptomyces griseoruber, Streptomyces capil- } \\
\quad \text { lispiralis } \mathrm{Ca}-1\end{array}$ & Actinomycetes & Extracellular & $\begin{array}{l}\mathrm{Cu} \\
\mathrm{Au}\end{array}$ & - & $\begin{array}{l}{[103]} \\
{[104]}\end{array}$ \\
\hline Schizophyllum radiatum, & Fungi & Extracellular & $\mathrm{Ag}$ & - & {$[105]$} \\
\hline Rhizopus oryzae & Fungi & Extracellular & $\mathrm{Au}$ & - & [109] \\
\hline Candida utilis NCIM 3469 & Yeast & Extracellular & $\mathrm{Ag}$ & $20-80$ & [111] \\
\hline Candida lusitaniae & Yeast & Extracellular & $\mathrm{Ag}$ & $2-10$ & [112] \\
\hline
\end{tabular}

Table 3 Plant-mediated greener nanoparticles

\begin{tabular}{llllll}
\hline Plant & Origin & Mode & Metal & Size (nm) & Reference \\
\hline Andrographis paniculata & Leaves & Extracellular & $\mathrm{Ag}$ & $40-60$ & {$[132]$} \\
Brassica oleracea & Arial parts & Extracellular & $\mathrm{Ag}$ & 36 & {$[133]$} \\
Camellia sinensis & Leaves & Extracellular & $\mathrm{ZnO}$ & $9-17.5$ & {$[134]$} \\
Sapium sebiferum & Leaves & Extracellular & $\mathrm{Pd}$ & $2-14$ & {$[135]$} \\
Spinacia oleracea & Leaves & Extracellular & $\mathrm{ZnO}$ & 40.9 & {$[136]$} \\
Alternanthera dentate & Leaves & Extracellular & $\mathrm{Ag}$ & $50-100$ & {$[131]$} \\
Euphorbia nivulia & Plant & Extracellular & $\mathrm{CuO}$ & - & {$[130]$} \\
\hline
\end{tabular}

high resistance to gold ions toxicity and can synthesize silver nanoparticle (AuNPs) efficiently. Sintubin et al. suggested that the cell wall of the bacteria may act as a capping agent for the production of NPs, stabilizing them by preventing aggregation. These author also shows the reduction process and the formation of nanoparticle may stimulate when there is an increase in the $\mathrm{pH}$ of the culture medium [99]. Generally, actinomycetes are used for the synthesis of extracellular enzymes and secondary metabolites [100] as well as they have ability for the biosynthesis of nanoparticles as they have unparalleled ability for the production of different bioactive compounds and contain high protein content. In 2012, Otari et al. prepared the silver nanoparticles by using Actinobacteria Rhodococcus NCIM 2891 [101] with the size range of $10 \mathrm{~nm}$ and spherical shape. Buszewski et al. prepared stable spherical shaped silver nanoparticle with the size range of 8 to $48 \mathrm{~nm}$ by using acidophilic actinobacteria, Streptacidiphilus durhamensis [102]. The recent reports described the synthesis of copper and gold nanoparticles using actinomycetes of Streptomyces griseoruber and Streptomyces capillispiralis Ca-1, respectively [103, 104].

\subsubsection{From fungi and yeast}

Fungal biosynthesis of nanoparticles is another easy and uncomplicated approach which has been promoted extensively for the production of nanoparticles. For the nanoparticle synthesis, fungi have higher productivity and higher tolerance to metals when compared with bacteria [105] as well as have the ability of higher bioaccumulation towards metal ions that leads to the production of nanoparticle that is efficient as well as low cost. Trichoderma viride reported AuNP biosynthesis within $10 \mathrm{~min}$ at $30^{\circ} \mathrm{C}$ and have a property of catalyst (biocatalyst) and strong anti-microbial agents. Metuku et al. have reported white 


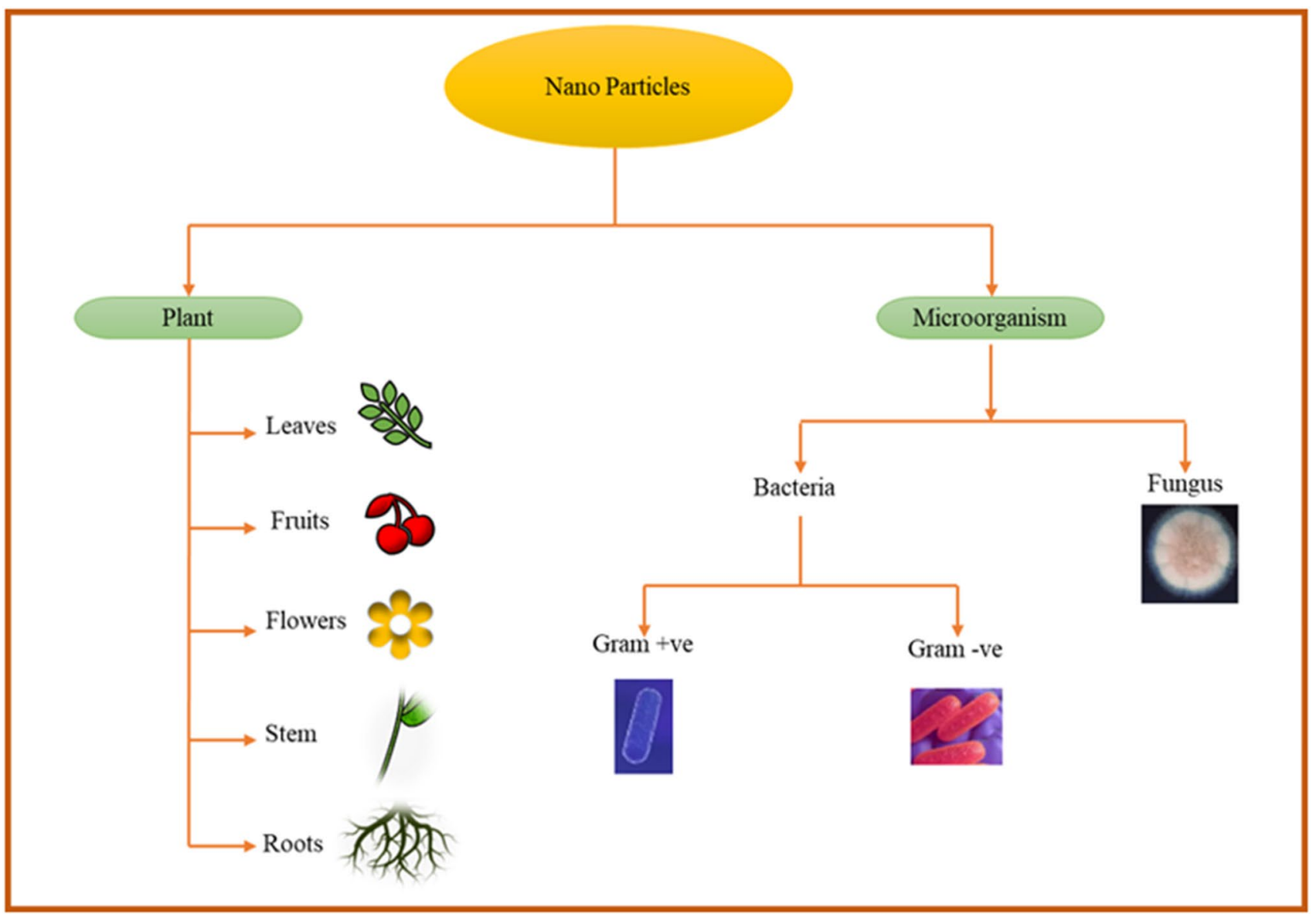

Fig. 5 Biosynthesis of MNPs

rot fungus and Schizophyllum radiatum, which have the ability of producing well-dispersed stable silver nanoparticles [106]. Candida albicans extract was used to prepare the Au and AgNPs [107] and the resulting nanoparticles are monodisperse and highly crystalline; the selenium nanoparticles (SeNPs) with the diameter range of $500 \mathrm{~nm}$ were prepared by using marine fungus Aspergillus terreus [108]. Kitching et al. reported the in vitro production of gold nanoparticles by using Rhizopus oryzae (cell surface proteins) as it has biomedical and bio catalytic applications [109]. Yeast has the ability to absorb and collect high concentrations of toxic metal ions from their surroundings [110]. Waghmare et al. reported the extracellular biosynthesis of AgNP using Candida utilis NCIM 3469. The obtained nanoparticles possess circular shape with a size range between 20 and $80 \mathrm{~nm}$ and they have anti-bacterial activity against some pathogenic strains (Staphylococcus aureus) [111]. In 2016, Eugenio et al. extract a yeast strain, Candida lusitaniae from the gut of a termite and show the production of silver nanoparticles with a diameter in the range of 2-10 $\mathrm{nm}$ [112].
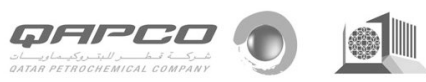

Qـامبر

\subsubsection{From virus}

Viruses can be employed for the preparation of nanoconjugates and nanocomposites with metal nanoparticles which are important materials in drug delivery and cancer therapy. The structural and biochemical stability of plant viruses provides a safe nanotechnology application as well as its ease of cultivation and non-toxicity in animals and humans. Cao et al. used red clover necrotic mosaic virus (RCNMV) for the synthesis of nanoparticles for the controlled delivery of doxorubicin drug for cancer therapy [113] as well as Le et al. investigated the ability of potato virus $\mathrm{X}$ nanoparticles for the delivery of doxorubicin drug for cancer treatment [114].

\subsubsection{From plants}

Plants are rich in secondary metabolites (alkaloids, flavonoids, and phenolic acids). Some of the studies have shown that the metabolites act as reducing, capping and stabilizing agents and inhibit the aggregation and agglomeration of the MNPs (Fig. 6) [122-124]. The bio-reduction of metal NPs using plant sources involved into three main phases. The 
Fig. 6 Role of secondary metabolites in the formation of MNPs

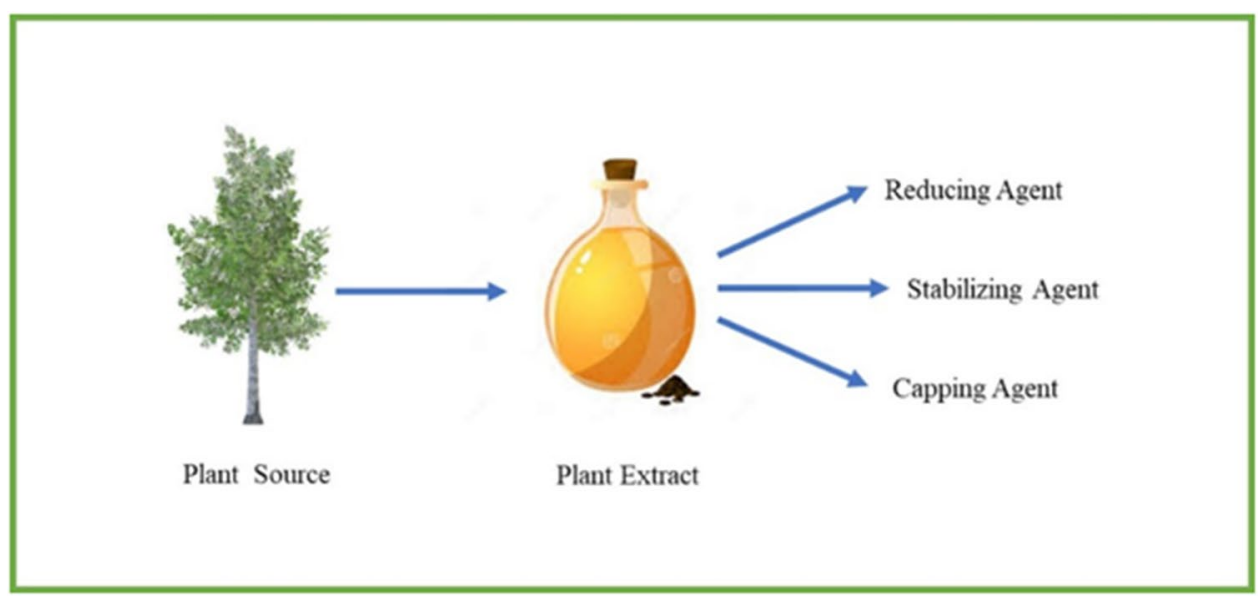

first one is activation step, another one is thermodynamic stability and the last one is termination phase [125]. The concentration of the plant extracts influence the arrangement of the formed nanoparticles as well as the temperature and $\mathrm{pH}$ of the plant extract control the size and growth of the nanoparticles [126]. El-Kemary et al. investigated the biosynthesis of AgNPs using a leaf extract of Ambrosia maritime, which are rich in secondary metabolites and have strongly influenced the NP yield [127].

The use of plants for the production of metallic nanoparticles has become more focused in recent years because of its rapid, environmentally friendly, pathogenic and economical protocol providing a single-step mechanism for biological process [128]. Relatively high levels of steroids, saponins, carbohydrates and flavonoids act as capping-reducing agents and phyto-constituents that provide stability to silver nanoparticles [129]. Copper oxide nanoparticles were synthesized extracellularly by using a medicinal plant extract of Euphorbia nivulia and the particles are stabilized by the terpenoids and peptides present within the latex [130]. The aqueous extract of Alternanthera dentate was used for the synthesis of silver nanoparticles with the size range of 50-100 nm. The extracellular silver nanoparticles were synthesized within $10 \mathrm{~min}$ [131].

The mechanism for the plant based biosynthesis of $n^{0}$ as zero valent metal atoms by extract polyphenols APOH when reacting with a metal halogen precursor is as follows:

$\mathrm{nAPOH}+\mathrm{nM}^{\mathrm{n}+} \rightarrow \mathrm{nAPX}+\mathrm{nM}^{0}$

\subsection{Factors influencing the greener synthesis of metallic nanoparticle}

Light: The rate of biosynthesis processes can affect when it has exposure to sunlight; for example, generally, the biosynthesis of $\mathrm{AgNps}$ was achieved at $12 \mathrm{~h}$ but exposure to sunlight reduced the reaction time up to $12 \mathrm{~h}$ to $5 \mathrm{~min}$. It was observed by Raut et al. [137].

Temperature and heating rate: The temperature can straightly affect the size, shape and rate of the formation of biosynthetic NPs [138]. For example, the size-selective synthesis of CuNPs could be achieved by adjusting the reaction temperature; the resulting nanoparticles have the diameters ranging from 5 to $25 \mathrm{~nm}$ as well as the shape of the CuNPs also change with the reaction temperature, enabling the formation of rod-shaped and cubical shape products [139].

$\mathrm{pH}$ : $\mathrm{pH}$ shows important effects on the shapes and sizes of NPs. For example, at pH 7, the gold nanoparticle was synthesized by using Rhodopseudomonas capsulate; it gives spherical shaped AuNPs but changing the $\mathrm{pH}$ to 4, it gives nanoplates. So changing of the $\mathrm{pH}$ value gives the different morphology and it has been proved by He et al. [120].

Time: Reaction time is also affecting the size and morphology of NPs. In increasing the reaction rate, the size and breadth of the synthesized nanoparticles can be reduced [140, 141].

\subsection{Toxicity of green nanoparticle}

The green nanoparticles can cause damage to the cell membrane, oxidative DNA damage and inhibit the electron transport chain as these have the ability to enter into cells and cause destruction when present above a threshold limit. However, the exact inhibition mechanism has not been demonstrated because there is limited available data on the biological activity of the green nanoparticles [142].

\section{Administration routes of drug delivery}

The choice of delivery route is driven by patient acceptance, drug properties (such as its solubility), access to a disease location, or efficacy in dealing with a specific disease 
(Fig. 7). There are several reports of drug delivery based on metal nanoparticles via transdermal drug delivery system (TDDS) and intravenous. Intravenous (IV) route is an invasive technique, although it has the advantage of avoiding drug dysfunction during the first pass metabolism and rapidly increasing drug concentration in a proper cycle. Compared to IV, TDDS offers many benefits, e.g., (1) the skin is easily accessible for absorption and it is harmless and patient-friendly and (2) TDDS drugs can be more systematically released into the system (146).

\subsection{Transdermal route}

In the skin, the penetration of drugs occurs by the process of spreading throughout the skin layers filled with byproducts. Basic properties of drugs manage molecular flow through these routes. The skin generally acts as a shield for efficient drug delivery, but there are other ways to achieve proper absorption. Various infiltration pathways are recognized in TDDS: (1) intercellular, (2) intra/trans cellular and (3) trans appendageal. Transdermal drug delivery avoids problems such as gastrointestinal irritation, metabolism, variations in delivery rates and disruption caused by food. It is also acceptable for patients under anesthesia. This technique is normally non-invasive and aesthetically acceptable and can be used to deliver local delivery for several days. Suksaeree et al. have reported silver nanoparticle (AgNP)-loaded antimicrobial wound dressing patch using ethyl cellulose as a matrix membrane and diethyl phthalate as a plasticizer. The anti-microbial wound dressing patch did not exhibit any interaction between the matrix membrane and AgNPs. The AgNPs were evenly dispersed in the patch. The patch
Fig. 7 Schematic representation of drug administrative route using MNPs

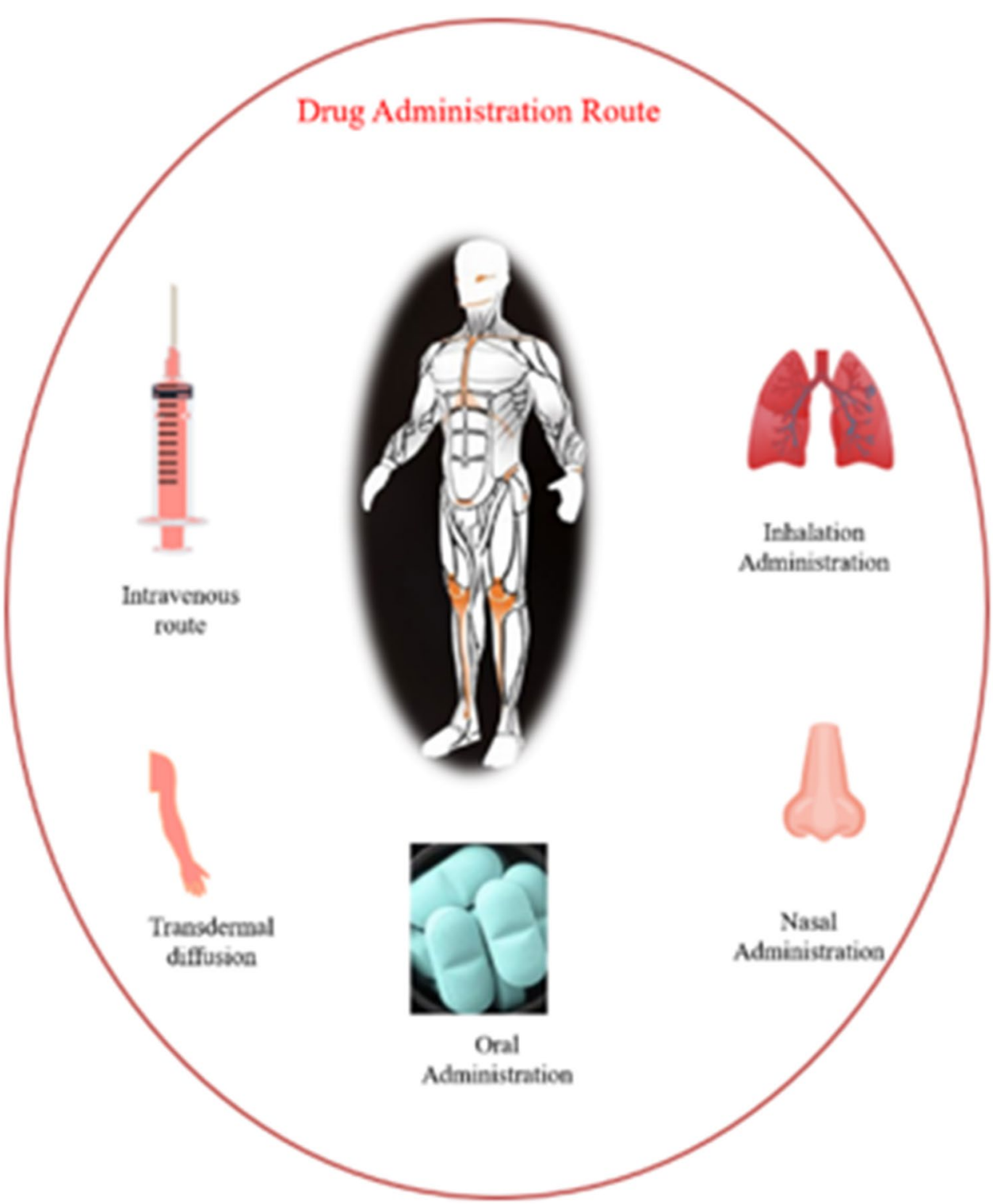


could control the release of silver at $102.98 \pm 4.11 \%$ over $12 \mathrm{~h}$ [143].

\subsection{Intravenous route}

MNPs can be administered using different routes namely intravenous, intraperitoneal injection, pulmonary inhalation and oral administration. The intravenous route delivers almost instantaneous response and permits systematic control of the rate of drug contribution into the body. It is also suitable for drugs which cannot be absorbed by the gastrointestinal tract or which cannot be injected into muscles or other tissues; equally important, it overcomes the problem of first-pass metabolism. Expensive drugs such as peptides and proteins are delivered efficiently by intravenous route. Intravenous administration overcomes the degradation by proteolytic enzymes. The main advantage of intravenous drug delivery is the rapid onset of action and complete bioavailability of drugs even with low doses. [144].

\section{Various metallic nanocarriers in drug delivery systems}

\subsection{Silver nanoparticles}

Silver is the most profit-oriented precious metal used in the preparation of NPs and nanomaterials. These are known because of their anti-bacterial, anti-viral, anti-fungal, antioxidant and unusually enhanced physicochemical properties compared to the bulk material such as optical, thermal, electrical and catalytic properties [145]. About $500 \mathrm{t}$ of silver nanoparticles (AgNPs), used in various industries and everyday life, is produced per year. Rising demand for silver nanomaterials requires the development of eco-friendly synthesis methods. AgNPs interrelate with microbes and discharge the silver ion in the de-activation of cellular-based enzymes, delayed membrane penetrability. Silver nanoparticles have been found to induce cytotoxicity via apoptosis and necrosis toward a range of different cell types. Moreover, they exhibit results against secondary effects of current therapies as well, such as deoxyribonucleic acid (DNA) damage, generation of reactive oxygen species (ROS), increasing leakage of lactate dehydrogenase (LDH) and inhibiting stem cell differentiation.

\subsubsection{AgNPs in cancer therapy}

Recent advancements in the field of oncology and therapeutic research of nanodiagnostic and nanotherapeutic agents have gave important improvements in the use of nanoscale metal particles as a solid carrier for the site-specific delivery of the drug release process [146]. Cancer is one of the leading causes of mortality in the modern world, with more than 10 million new cases every year. Anti-cancer activities of silver nanoparticles (AgNPs) are also being widely studied (Table 4). AgNPs have the ability to stimulate the production of reactive oxygen species (ROS) and thus destroying the mitochondrial respiratory chain of cancer cells. The (AgNPs) have proven promising anti-cancer effects [147]. Some researchers have reported that AgNPs induced a cytotoxic effect against leukemic cells. Guo et al. studied the PVP-coated AgNPs could effectively reduce the activity of acute myeloid leukemia (AML) cells and stimulate DNA damage and apoptosis through the generation of reactive oxygen species (ROS) and the release of silver ions. Sahu et al. reported the significant concentration-dependent cytotoxicity of AgNPs in human liver (HepG2) cells in the concentration range of 1 to $20 \mu \mathrm{g} / \mathrm{mL}$ [148]. El-Deeb et al. reported the simple, low cost and eco-friendly synthesis of AgNPs by using honey bees. The prepared nanocarrier was used for the treatment of colon carcinoma Caco- 2 cells. They noted that the obtained AgNPs could be safely used with concentrations up to $39 \mu \mathrm{g} / \mathrm{mL}$ with $60 \%$ inhibition
Table 4 AgNPs in anti-cancer therapy

\begin{tabular}{llll}
\hline S. no & Material used & Activity/cell line & Reference \\
\hline 1 & PVP-coated AgNPs & Acute myeloid leukemia (AML) cells & {$[149]$} \\
2 & AgNPs & Human liver (HepG2) cells & {$[148]$} \\
3 & AgNPs & Colon carcinoma Caco-2 cells & {$[149]$} \\
4 & AgNPs & Cytotoxic effect to MCF-7 breast cancer & {$[150]$} \\
5 & AgNPs & Colon cancer cells/ HCT116, Caco-2 and HT-29 & {$[152-155]$} \\
6 & AgPCA & HCT116 colorectal cells & {$[159]$} \\
7 & AgNPs-MTX & Lung cancer cell line (A-549) & {$[160]$} \\
8 & (MTX-GO/AgNPs) & Anti-cancer pharmacological activity & {$[161]$} \\
9 & Ag-NGO-DOX & HepG2 cancer cell line and HEK293 cell line & {$[163]$} \\
10 & DOX-AgNPs & Inhibition of the proliferation of cancer cells B16F10 & {$[164]$} \\
11 & IMAB-AgNPs & Cytotoxicity in MCF-7 cells & {$[165]$} \\
12 & AgNPs & Cytotoxicity and apoptosis in A2780 cells & {$[166]$} \\
\hline
\end{tabular}


of Caco-2 cell proliferation [149]. AgNPs have exhibited cytotoxic effect to MCF-7 breast cancer cells at $20 \mu \mathrm{g} / \mathrm{mL}$ for $48 \mathrm{~h}$ [150] and also its suppressed lung cancer cells, H1299 in which $50 \%$ of cells were killed at $5 \mu \mathrm{g} / \mathrm{mL}$ [151] In colon cancer cells, AgNPs have shown effective killings of 5 to $28 \mathrm{~g} / \mathrm{mL}$ in cell lines such as HCT116 [152], Caco-2 [153] and HT-29 [154] as well as AGNPs have been shown to have great potential to act as a nanocarrier to deliver anti-cancer drugs to cancer cells $[155,156]$. This evidence strongly supports the potential use of AGNPs for cancer chemotherapy [157]. K. X. Lee et al. prepared AgPCA (PCA: protocatechuic acid) by using Garcinia mangostana fruit peel extract. They reported AgNPs loaded with PCA (AgPCA) resulted in $80 \%$ of inhibition at $15.6 \mu \mathrm{g} / \mathrm{mL}$ as compared to AgNPs which only killed $5 \%$ of HCT116 colorectal cells at the same concentration [158].

Rozalen et al. [159] synthesized AgNPs (size of $11.13 \pm 2.3 \mathrm{~nm}$ ), then it is coupled with methotrexate (AgNPs-MTX) and it shows anti-cancer activity, and the lower dose of AgNPs-MTX was needed compared to free methotrexate, as well as the authors reported that the anticancer activity was more noticeable in the colon cancer cell line (HTC-116) than in the lung cancer cell line (A-549). Thapa et al. prepared the nanocomposite of AgNPs embedded in graphene oxide (GO) and coupled with methotrexate (MTX-GO/AgNPs). The nanocarrier combines the combined effect of AgNPs, which increase the production of reactive oxygen species that cause DNA damage, leading to improved cellular apoptosis. The combinational therapy system MTX-GO/AgNPs potentially evaluated for effective folate receptor-targeted treatment of cancers [160]. Palai et al. [161] synthesized AgNPs coupled with doxorubicin by utilizing a biosynthesis approach. The drug release by the nanosystem was studied at two different $\mathrm{pHs}$ of 7.4 and 5.4. From the result, at acidic $\mathrm{pH}$ higher rate of drug release was observed as well as at both $\mathrm{pH}$, it was possible to note a controlled release of doxorubicin up to $120 \mathrm{~h}$. The authors reported the synthesized nanocarriers had a less damaging effect on cancer cells of the HeLa cell line compared to free doxorubicin; it showed less cytotoxicity in the normal HaCaT keratinocyte cell line and the nanosystem shows less harmful effect on normal cells compared to free doxorubicin.

Zeng et al. (2018) [162] prepared AgNPs coated with graphene oxide (Ag-NGO) as doxorubicin nanocarriers. The Ag-NGO-DOX nanocarrier has the potential to deliver the drug and released it at a targeted location, due to the intracellular acidic $\mathrm{pH}$ responsive release of DOX, making viable the drug to reach the nucleus of cancer cells (HepG2 cancer cell line and HEK293 cell line). In 2015, Patra et al. [163] synthesized AgNPs by using Butea monosperma leaf extract, then the AgNPs were coupled with doxorubicin. The DOX-AgNPs nanosystem produced greater inhibition of the proliferation of cancer cells B16F10 of murine melanoma, and MCF-7 than free doxorubicin. In 2017, Shandiz et al. [164] synthesized AgNPs coupled with imatinib (IMAB) through biosynthesis (Eucalyptus procera extract) method. The authors finalize that the IMAB release could be split into two stages. In the first stage, till $\sim 40 \mathrm{~h}$, there was a burst release of the drug and in the second stage; the drug release was gradual till a release of $86.56 \pm 2.04 \%$ at $80 \mathrm{~h}$ of contact time in a releasing inducing medium of phosphate buffer. The IMAB-AgNPs show greater cytotoxicity in MCF-7 cells than the free drug of imatinib.

Yu-Guo Yuan and collaborators have shown that the synergism between AgNPs and gemcitabine generated a higher cytotoxicity and apoptosis in A2780 cells, compared with the use of the therapeutic agent without nanoparticles [165]. Moreover, it was demonstrated that AgNPs can improve the responsiveness to gemcitabine or salinomycin in ovarian cancer cells, leading to an increased level of different proapoptotic genes, such as tumor protein p53, p21, Bax, Bak, and activation of caspases 3 and 9. The synergistic effect between silver nanoparticles and camptothecin in human cervical cancer cells (HeLa) was inferred from their ability to activate caspases 9,6 , and 3. Moreover, increased levels of p53, p21, cyt C, Bid, Bax, Bak and modulated expressions of Akt1, RAF, MEK, Erk1/2, JNK, P38, NF-kB and Cyclin D which are known as molecules involved in cell survival were observed in HeLa cells after using AgNPs combined with camptothecin [166]. AgNPs are also active significant therapeutics for HIV infection treatment. AgNPs induce anti-viral properties through the binding process to gp120 with the subsequent inhibition of CD4-reliant.

\subsubsection{AgNPs as anti-viral agents}

The development of resistance by various viral pathogens against anti-viral agents signifies another main cause of death, which is a major concern of the pharmaceutical, medical and biotechnological systems [166]. In recent years, there is a tremendous growth in the emerging applications of AgNPs as anti-viral agents, due to their inhibitory efficacy against numerous viruses, including certain strains of hepatitis, coronavirus, influenza, herpes, recombinant respiratory syncytial virus and human immunodeficiency virus [167]. It is widely accepted that AgNPs contribute towards the inhibition of virus because of effective interactions with sulfhydra, amino, carboxyl, phosphate and imidazole groups. A delivery system was designed at nanoscale with AgNPs for zanamivir medication which is commonly used to treat and prevent influenza virus. Similarly surface enrichment of the AgNPs with amantadine was developed to avoid the resistance shown by H1N1 virus [168]. Compared with single drug treatments, self-assembly of amantadine and zanamivir over the surface of AgNPs produces better inhibitory potential of neuraminidase and hemagglutinin activity. 


\subsection{Gold nanoparticles}

Gold nanoparticles (AuNPs) are effective radiosensitizers in medical applications such as drug delivery and cancer therapy [169]. Au NPs can deliver multiple drug molecules, recombinant proteins, vaccines or nucleotides into their targets and can control drug release via biological stimuli (internal) or light activation (external). Au NPs are known to be an effective nanocarrier for various drugs such as peptides, plasmid deoxynucleic acids (pDNAs), proteins, small interfering ribonucleic acids (siRNAs) and chemo-therapeutic agents. AuNP-based drug delivery has gained considerable attention because of its prominent performance [170]. Gold particles that are modified with nuclear localization signal from simian virus (SV40) have been widely used for drug carrier to nucleus. Surface functionalization is one of the most favorable properties of Au NPs in the biomedical domain [171].

\subsubsection{AuNPs in cancer therapy}

For gold nanoparticles to be effective as a pharmaceutical, it is essential to have a firm understanding of their biodistribution/accumulation in living systems. To achieve this, it is necessary to have proper characterization of the nanomaterials and a good animal model with an appropriate sample size and robust statistical analyses. The use of gold nanoparticles (AuNPs) reduces the risk of side effects and controls the damage to healthy cells [172]. AuNPs are a novel factor in cancer therapy and show aggregation [173] and size-dependent cytotoxic activity against various cancer cells [174, 175]. The mechanism beyond the anti-cancer activity of AuNP is quite difficult and not well understood. AuNPs have positive charges, while cancer/normal cell membranes contain negatively charged substances such as lipids having counter-charges is responsible for taking over and internalizing AuNPs [176]. Another way for gold nanoparticles to enter cells is by endocytosis as shown in the study, endocytosis causes small AuNPs to accumulate within HeLa cells [177]. The surface of AuNPs can be functionalized with various biomolecules such as DNA, peptides and antibodies. For example, 13-nm colloidal Au has been combined to methotrexate which is an analog of folic acid and has the ability to restrain the growth and reproduction of cancer cell and has been usually used as an anti-cancer drug. Gold nanoparticles containing cedoximab and gemcitabine (anti-cancer drugs) were developed for TDDS and were able to inhibit pancreatic tumor cells in vitro and tumor model [178]. Eghtedari et al. have fabricated the AuNPs for in vivo targeting to breast cancer cells. Herceptin was used to functionalize the AuNPs by molecular recognition of breast cancer cells along with PEG [179].

\subsubsection{AuNPs in the treatment of bacterial infections}

Due to the development and extent of drug resistance by bacterial pathogens, it resulted in the decrease in effectiveness of antibiotics over period of time. The so-called "antibiotic resistance crisis" caused by drug-resistant bacteria results in additional medical costs of up to billions of dollars annually [180]. AuNPs exhibit a combination of physical, chemical, optical, and electronic properties unique from other biomedical nanotechnologies and provide a highly multifunctional platform in drug delivery systems as joint anti-bacterials [181]. Gentamicin sulfate is an aminoglycoside and has a broad range of anti-bacterial activities. However, gentamicin sulfate has some serious side effects such as ototoxicity and nephrotoxicity, which restrict its usage. It also does not make cell membrane efficiently and is highly soluble to water. Gentamicin can be used for the treatment of serious microbial infection when it is conjugated to $\mathrm{Au}$ NPs [182]. Ampicillin functionalized AuNP prepared by Brown et al. was an effective broad-spectrum fungicide that can resist Gram-negative and Gram-positive bacteria. This functionalization method mainly utilizes ampicillin's ability to permeate the outer membrane of bacteria. Nanoparticles enter the bacteria to achieve anti-bacterial effects. This combined anti-bacterial effect can destroy ampicillin-resistant bacteria [183].

\subsubsection{AuNPs in the treatment of diabetes and inflammation}

Govindaraju et al. synthesized guavanoic acid functionalized gold nanoparticles and the strong in vitro anti-diabetic activity of guavanoic acid functionalized gold nanoparticles was studied by using L6 rat skeletal muscle cell lines. The active nanoparticles of guanonic acid have been found to enhance the function of insulin-dependent glucose uptake [184]. Yujie Zhang et al. prepared the two types of glucose-responsive high-drug loading AuNCs (gold nanocluster) which were produced for insulin release. The first type of AuNCs was synthesized based on CR9 peptide and it was coupled with 4-carboxy-3-fluorophenylboronic acid (FPBA-COOH) and insulin molecules to obtain AuNC nanocomplex drug namely, (CR9-AuNC-FPBA-Ins) and the second type of AuNCs was synthesized based on bovine serum albumin (BSA), the carboxyl-enriched BSA-AuNCs were coupled with 4-aminophenylboronic acid (NH2-PBA) molecules and insulin, labeled as BSA-AuNC-PBA-Ins and then the micro needle (MN) patch was loaded with the above AuNC nanocomplex drugs. The authors have successfully reported the soluble and glucose-responsive insulin-releasing MN patch system for the treatment of type 1 diabetes. MNs are fused with high-drug loading AuNC nanocarrier drugs, where gold nanomaterials enhance the mechanical strength of MNs to effectively penetrate the skins of mice [185]. Similarly they

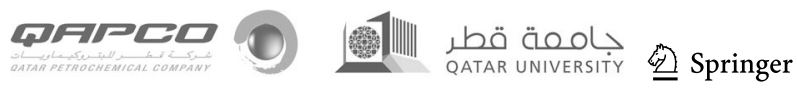


developed a gold nanocluster (GNCs) based glucose-responsive insulin releasing system for glucose control in diabetes. The GNCs prepared with one-step reaction and the GNCs are coupled with the following materials like 4-carboxyphenylboronic acid (PBA) and 4-carboxy-3-fluorophenylboronic acid (FPBA). Complex prepared for glucose-responsive insulin release and glucose regulation in diabetes. This nanocomplex has the ability to release insulin quickly into the hyperglycemic state and effectively maintains blood glucose levels in the type 1 diabetic mice at the normoglycemic level for up to $48 \mathrm{~h}$ [186].

Nanoparticles have the ability to penetrate epithelial cells and inflammatory cells resulting in better efficacy and better durability in the treatment. They also have the best selection of target sites such as inflammatory cells or tissues [187]. Kim et al. prepared methotrexate (MTX)-loaded Au/Fe/Au plasmonic nanoparticles coupled with arginylglycylaspartic acid (RGD) for magnetic targeted chemo-photothermal treatment of rheumatoid arthritis. Under near-infrared (NIR) irradiation, the Au half-shell produces heat at the inflammation area and speeds up the release of MTX. Fe half-shell can deliver nanoparticles to swollen joints under the action of an external magnetic field and increase their residence time in the joints. The study combined the use of low-infrared radiation and external magnetic field so that a low-dose MTX can achieve the best therapeutic effect for arthritis [188].

\subsection{Palladium nanoparticles}

To overcome the inherent limitations of conventional drug therapies with many limitations, such as low selectively, rapid excretion and severe toxicity, the controlled drug delivery system has been gaining attention. Pd is a very precious metal with extraordinary catalytic, powerful mechanical and electroanalytical properties [189]. Pd nano-based structures have been developed as self-therapeutics, with proven anti-bacterial and cytotoxic pharmacological activity [190]. The high porosity of PdNPs was the genius property for loading anti-cancer drugs. The therapeutic drug can be indirectly conjugated to the PdNPs through a linking molecule. Shanthi et al. have developed $\mathrm{pH}$ responsive carrier of palladium NPs with DOX through acid labile linkage and exhibited $\mathrm{pH}$-mediated release of doxorubicin in endosomal compartment of drug-resistant cervical cancer cells [191]. For example, Dox, which was glued to PEGylated PdNPs through a hydrazine bond, showed a $\mathrm{pH}$-responsive releasing profile in human cervical cancer cells (HeLa) and strong anti-tumor efficacy against HeLa tumor xenograft models in vivo. As mentioned earlier PdNPs possess anti-cancer activity on various cancer cell lines resulting in potential toxicity, which may affect the results of drug-delivery studies. The effect of cancer drug on targeted cells/tumors need to be carefully examined by correlating the cytotoxicity of mono-modal PdNPs as self-therapeutics and that of dualmodal cancer drug-loaded PdNPs. The in vitro experiment revealed that $20 \mu \mathrm{g} / \mathrm{mL}$ of PdNPs which was synthesized by chaga mushroom extract was able to kill approximately $20 \%$ of HeLa cells; meanwhile, $30 \%$ of HeLa cells were killed by the Dox-loaded PdNPs (20 $\mu \mathrm{g} / \mathrm{mL}$ of Pd).

\subsection{Platinum nanoparticles}

Platinum nanoparticles (PtNPs) are noteworthy scientific tools that are being explored in various biotechnological, nanomedicinal and pharmacological fields. They are unique because of their large surface area and their numerous biomedical applications as anti-microbial, antioxidant and anticancer properties [192]. However, recent reports have demonstrated the toxicity of PtNPs, limiting the use of PtNPs in healthcare and medicine. As a consequence, it is an ultimate challenge to design and develop biocompatible PtNPs for cancer therapy [193]. Another key challenge in drug delivery is low circulation and retention of nanoparticles and nanodrug conjugates inside tumors limiting the efficacy of the nanomedicine [194]. Generally, these nanoconjugates are often cleared from the body in a short time following their recognition by the immune system. In this context, pegylation (PEG is FDA approved) of nanoparticles has become a popular technique; which increases the blood circulation and retention time and decreases rapid clearance and non-specific interactions with serum proteins. Mukherjee et al. have reported improved delivery of doxorubicin using rationally designed PEGylated platinum nanoparticles for the treatment of melanoma. Intraperitoneal (IP) administration of PtNPs-DOX shows substantial reduction of tumor growth in subcutaneous murine melanoma tumor model compared to control group with free drug. Upregulation of tumor suppressor protein p53 and downregulation of SOX2 and Ki-67 proliferation markers in melanoma tumor tissue indicates probable molecular mechanism for the anti-cancer activity of PtNPs-DOX [195].

\subsection{Copper nanoparticles}

Copper nanoparticles (CuNPs) have gradually become an active area of research due to their unique physical, chemical, electrical and optical properties, low cost, availability and exhibit good anti-bacterial properties [196, 197]. The prime advantage of CuNPs is their low cost and its availability compared to gold and silver nanoparticles, resulting in the sample synthesis and various applications of CuNPs [198, 199]. Copper is a readily available metal and one of the essential trace elements in most living organisms. Experimental studies on the development of targeted drug delivery and bioimaging molecules resulted in the formation of transferrin (Tf) templated copper nanoclusters (Tf-CuNCs) with 
enhanced luminescence. The corresponding nanomolecules were further formulated into spherical transferrin copper nanocluster-doxorubicin (Dox) NPs (Tf-CuNC-Dox-NPs) of spherical shape, based on the electrostatic interactions with doxorubicin. The newly synthesized nanomaterials were further assessed in vivo on TfR (transferrin receptor) positive DLA (Dalton's lymphoma ascites) bearing mice revealing enhanced inhibition of tumor growth and prolongation of the survival of the animals [200]. Kamble et al. have reported curcumin-capped CuNPs as possible inhibitors of human breast cancer cells and angiogenesis: a comparative study with native curcumin [201]. Vikram et al. mupirocin coupled copper nanoparticles were synthesized to overwhelm drug resistance in Staphylococcus aureus, responsible for dermal skin infections. In vitro release study of CuNPs shows $96.5 \%$ release of drug and show effective anti-bacterial activity against Staphylococcus aureus [202].

\subsection{Zinc oxide nanoparticles}

Zinc oxide $(\mathrm{ZnO})$ NPs have promising approach in drug delivery system in cancer, diabetes, and inflammation therapy. Zhang et al. have synthesized ZnO NPs as a drug carrier for the anti-cancer drug daunorubicin (DNR) by using simple one-step process at room temperature in the presence of air. The investigation discloses that the combination of $\mathrm{ZnO}-$ NPs-DNR has stimulated a significant reduced cytotoxicity of anti-cancer drug and considerable increase in the cancer cell targeting mediated by ROS in human hepatocarcinoma cells (SMMC-7721 cells) [203]. J. Hussein et al. synthesized green $\mathrm{ZnO}$ NPs using the solid state approach in the dry state capped by gum arabic (GA) exhibit as an excellent anti-diabetic agent with high cytocompatibility as a nanodelivery system. Following this, hydrophobic docosahexaenoic acid (DHA) was loaded on ZnO NPs to investigate the antidiabetic efficacy of free DHA compared with loaded DHA NPs. The blood glucose, insulin resistance, oxidant and antioxidants, cholesterol, triglycerides, fatty acid parameters and phosphoinositide 3-kinase (PI3K) levels are demonstrated in the preparation of diabetes in experimental rats. It confirms that the biocompatibility and physicochemical properties of zinc oxide nanoparticles played a significant role in the treatment of diabetes [204]. P. Chauhan et al. have investigated the changes assisted by the treatment of streptozotocin influenced diabetic rats with nanocurcumin-zinc oxide (ZnO-NC) nanoparticles, encapsulated in chitosan (CS-ZnO-NC) on different biomarkers associated to the metabolic and oxidative accelerations were observed in this experimental model (streptozotocin induced diabetic Wistar rats) of diabetes mellitus. The CS-ZnO-NC is useful for the treatment of diabetes mellitus and has no toxicity [205]. Ekta Yadav et al. have prepared ZnO NPs by using Trianthema portulacastrum Linn. (TP) plant extract via co-precipitation method. These greener nanoparticles showed strong in vitro anti-inflammatory activity. Topical treatment with ZnOTP on injured skin tissue led to rapid closure and wound healing due to reduced collagen fibers, tissue granulation, antioxidant pressure, and inflammatory reactions [206].

\subsection{Titanium dioxide nanoparticles}

Titanium dioxide $\left(\mathrm{TiO}_{2}\right)$ or titania is a semiconductor metal oxide with potential applications in drug delivery systems especially in cancer because of its chemical stability as well as low-toxicity and low cost [207, 208]. Titanium dioxide exists in two crystalline forms namely rutile and anatase which is chemically more active. Rutile form of $\mathrm{TiO}_{2}$ nanoparticles can also be called as titanium dioxide fine particles $\left(\mathrm{TiO}_{2} \mathrm{FPs}\right)$. With the increase in crystalline nature of anatase form, there is an increase in the generation of reactive oxygen species which substantially makes the anatase phase more toxic to healthy cells when compared to rutile phase. The rutile titanium dioxide is considered as chemically inert but when the particles become smaller, the surface area will increase and therefore the rutile titanium dioxide particles can become harmful, according to the studies. Also, the chemical changes carried out on the surface of nanoparticles cause alterations in the overall activity of $\mathrm{TiO}_{2}$ NPs [209]. Various nanostructures of $\mathrm{TiO}_{2}$ like $\mathrm{TiO}_{2} \mathrm{NPs}$, $\mathrm{TiO}_{2}$ nanotubes, $\mathrm{TiO}_{2}$ matrices, as well as $\mathrm{TiO}_{2}$ capsules and $\mathrm{TiO}_{2}$ whiskers $\left(\mathrm{TiO}_{2} \mathrm{Ws}\right)$ have emerging applications as drug delivery systems for different anti-cancer drugs, such as gambogic acid (GA), cisplatin, valproic acid, doxorubicin (DOX), temozolomide (TMZ) and daunorubicin (DNR). For example, one-dimensional $\mathrm{TiO}_{2}$ Ws clearly enhanced the cytotoxic effects of DNR by increasing its dose inside human SMMC-7721 hepatocarcinoma cells [210]. Similarly the anti-tumor efficacy of TMZ, a therapeutic drug for brain gliomas, could be improved by coupling the TMZ with $\mathrm{TiO}_{2}$ nanostructures [211]. In addition to this encapsulation of valproic acid into $\mathrm{TiO}_{2}$ matrices led to gradual but long lasting release of valproic acid in numerous diseases [212, 213]. Moreover, $\mathrm{GA}$ and $\mathrm{DNR}$ from $\mathrm{GA}^{-\mathrm{TiO}_{2}}$ and $\mathrm{DNR}-\mathrm{TiO}_{2}$ nanocomposites represented more potential anti-tumor efficiency in human leukemia K562 cells, when compared with its individual drugs $[214,215]$.

\subsection{Metal sulfide nanoparticles}

Metal sulfide nanomaterials (MeSNPs) are a novel class of metal-containing nanomaterials composed of metal ions and sulfur compounds [216, 217]. During the past decade, scientists found that the MeSNPs engineered by specific approaches not only had high biocompatibility but also exhibited unique physicochemical properties for cancer therapy. Yang et al. have reported engineered polydopamine

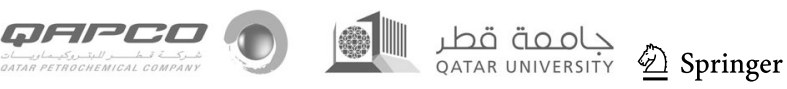


(PDA)-coated hollow mesoporous nickel sulfide (NiS) NPs (hm-NiS) for the delivery of doxorubicin (DOX) [218]. The encapsulation efficiency and loading capacity of DOX were respectively estimated as 66.9 and $7.1 \%$. The high efficiency of drug encapsulation not only resulted from the internal cavity and hollow mesoporous structural framework of hmNiS but also from the strong interaction between DOX and PDA. Li et al. designed a kind of mesoporous hollow $\mathrm{CuS}$ nanoparticles (H-CuS NPs) for delivering chlorine6 (Ce6, a kind of photosensitizer) and DOX to tumor sites [219]. The thermo-responsive degradation feature of $\mathrm{H}-\mathrm{CuS} \mathrm{NPs}$ could trap drugs interiorly in the cavity of H-CuS nanovehicles, thus functioning as a removable plug and thereby attained the controlled release of drugs by light-induced thermal stimuli. The attribute was highly useful for targeted delivery of the drug, which only caused a minimal release of drug non-specifically in the circulation, thereby enhancing the drug bioavailability in tumor tissues via improved permeability and retention effects. Hou et al. have reported copper sulfide nanoparticle-based localized drug delivery system as an effective cancer synergistic treatment and theranostic platform [220]. They introduced diffusion molecular retention (DMR) tumor targeting effect, a new strategy that employed transferrin (Tf)-modified hollow mesoporous $\mathrm{CuS}$ nanoparticles (HMCuS NPs) to undergo extensive diffuse through the interstitium and tumor retention after a peritumoral (PT) injection. The results exhibited that TfHMCuS NPs prolonged the local accumulation and retention together with slow vascular uptake and extensive interstitial diffusion, which was consistent with the biodistribution studies of AS/Tf-HMCuS NPs. Xie et al. engineered a kind of twodimensional tin sulfide nanosheets ( $\mathrm{SnS}$ NSs) with a high loading rate of DOX (up to about $200 \%$ in weight) through electrostatic absorption between the negative potential carriers and positively charged DOX [221], which was larger than that of mesoporous MeSNs (about 7\%).

\subsection{Nanoscale metal organic frameworks}

Metal organic frameworks (MOFs) are considered as a potential class of nanocarriers for drug delivery owing to well-defined structure, ultrahigh surface area and porosity, tunable pore size, and easy chemical functionalization [222]. Recently, these materials have been scaled down to nanometer sizes, and this results in the production of nanoscale metal-organic frameworks (NMOFs) for biomedical applications [223]. The unique properties of NMOFs such as large pore volume, highly ordered structure and large surface area enable them to adsorb functional molecules on their external surface or open channels, as well as trap these molecules inside the framework [224]. NMOFs possess several potential advantages over conventional nanomedicines such as their structural and chemical diversity, their high loading capacity, and their intrinsic biodegradability [225]. To increase the biological functionality and biocompatibility functionalization of MOFs with biomolecules such as nucleobases, saccharides, peptides, and amino acids have been employed as the organic ligands to prepare bio-MOFs. Zirconium-based MOF was prepared as a nanocarrier for the controlled release of ibuprofen in an acidic phosphate buffer solution [226]. Horcajada and collaborators reported the use of a series of non-toxic porous iron (III)-based nanoMOFs [227], i.e., MIL-53, MIL-88A, MIL-88Bt, MIL-89, MIL-100 and MIL-101- $\mathrm{NH}_{2}$, as carriers of antineoplastic and retroviral drugs, including busulfan, azidothymidine triphosphate, doxorubicin or cidofovir, ibuprofen, etc. ZIF-8 (Zeolitic Imidazolate Framework) is an outstanding representative for drug delivery, which is constructed by zinc ions and 2-methylimidazole and possesses unique merits such as high porosity and stability, good biosecurity, and $\mathrm{pH}$-induced degradability. Recently, Willner and co-workers encapsulated two drugs (e.g., insulin and anti-vascular endothelial growth factor aptamer (VEGF aptamer) and glucose oxidase (GOx) into ZIF-8 nanoparticles to build a glucose-responsive vehicle for drug controlled release [228]. Zhuang et al. have reported optimized metal organic framework nanospheres for drug delivery. Camptothecin encapsulated ZIF-8 particles show enhanced cell death, indicative of internalization and intracellular release of the drug [229].

\section{Conclusion}

The interdisciplinary multifunctional nature of nanotechnology and nanodrugs enabled diversification and advancements to improve the quality of life. However at present, the basic theory of nanotechnology applied in medicine and the preparation of nanodrugs are not fully explored. Therefore, extensive research has to be carried out in the field of nanomedicine especially in drug delivery systems. Nanomedicine is constantly looking for new and improved treatments for diseases, which need to have a high efficacy and be cost-effective, creating a large demand on scientific research to discover such new treatments. One important aspect of any treatment is the ability to be able to target only the illness and not cause harm to another healthy part of the body. Nowadays, there is a tremendous improvement in the utilization of metal nanoparticles as targeted drug delivery systems because of their availability, biocompatibility, and stability. These behaviors allow the drugs to be encapsulated and delivered straightly to the targeted sites thereby produces higher biological effect. The development of metallic nanoparticles is rapid and multidirectional and the improved practical potential of metallic nanoparticle highlights their potency as new tools for future drug delivery therapeutic 
modalities especially in the cancer, inflammation, diabetes and anti-viral therapy.

Acknowledgements The authors sincerely thank the management of Kalasalingam Academy of Research and Education for their constant encouragement and support and providing all the necessary facilities for carrying out this research work.

\section{Declarations}

Conflict of interest The authors declare no competing interests.

\section{References}

1. K. Ibrahim, S. Khalid, K. Idrees, Nanoparticles: properties, applications and toxicities. Arab. J. Chem. 12, 908-931 (2019)

2. O.V. Salata, Applications of nanoparticles in biology and medicine. J. Nanobiotechnology. 2, 1-6 (2004)

3. E.C. Wang, A.Z. Wang, Nanoparticles and their applications in cell and molecular biology. Integr Biol (Camb). 6, 9-26 (2014)

4. D. Nath, P. Banerjee, Green nanotechnology-a new hope for medical biology. Environ Toxicol Pharmacol. 36, 997-1014 (2013)

5. B. Felice, M.P. Prabhakaran, A.P. Rodríguez, S. Ramakrishna, Drug delivery vehicles on a nano-engineering perspective. Mater. Sci. Eng. C 41, 178-195 (2014)

6. S.R. Choudhury, J. Ordaz, C.L. Lo, N.P. Damayanti, F. Zhou, J. Irudayaraj, Zinc oxide nanoparticles-induced reactive oxygen species promotes multimodal cyto- and epigenetic toxicity. Toxicol. Sci. 156, 261-274 (2017)

7. S. Qadri, Y. Haik, E. Mensah-Brown, G. Bashir, M.J. FernandezCabezudo, B.K. al-Ramadi, Metallic nanoparticles to eradicate bacterial bone infection. Nanomed. Nanotechnol. 13, 2241-50 (2017)

8. K.B. Ramadi, Y.A. Mohamed, A. Al-Sbiei, S. Almarzooqi, G. Bashir, A. Al Dhanhani, Acute systemic exposure to silver-based nanoparticles induces hepatotoxicity and NLRP3-dependent inflammation. Nanotoxicology 10, 1061-74 (2016)

9. N. Martinho, C. Damge, C.P. Reis, Recent advances in drug delivery systems. J. Biomater. Nanobiotechnol. 2, 510-526 (2011)

10. H. Jahangirian, E.G. Lemraski, T.J. Webster, R. RafieeMoghaddam, Y. Abdollahi, A review of drug delivery systems based on nanotechnology and green chemistry: green nanomedicine. Int. J. Nanomed. 12, 2957-2978 (2017)

11. S. Jinjun, V.R. Alexander, F.C. Omid, L. Robert, Nanotechnology in drug delivery and tissue engineering: from discovery to applications. Nano Lett. 10, 3223-3230 (2010)

12. S. Qadri, T. Abdulrehman, J. Azzi, S. Mansour, Y. Haik, AgCuB nanoparticle eradicates intracellular $\mathrm{S}$. aureus infection in bone cells: in vitro. Emergent. Mater. 2, 219-31 (2019)

13. S. Parveen, R. Misra, S.K. Sahoo, Nanoparticles: a boon to drug delivery, therapeutics, diagnostics and imaging. Nanomed. Nanotechnol. 8, 147-166 (2012)

14. M. Noruzi, D. Zare, K. Khoshnevisan, D. Davoodi, Rapid green synthesis of gold nanoparticles using Rosa hybrida petal extract at room temperature. Spectrochim. Acta A: Mol. Biomol Spectrosc. 79, 1461-1465 (2011)

15. S. Al Tamimi, S. Ashraf, T. Abdulrehman, A. Parray, S.A. Mansour, Y. Haik, Synthesis and analysis of silver-copper alloy nanoparticles of different ratios manifest anticancer activity in breast cancer cells. Cancer Nanotechnol. 11, 1-16 (2020)
16. K.B. Narayanan, N. Sakthivel, Biological synthesis of metal nanoparticles by microbes. Adv. Colloid Interface Sci. 156, 1-13 (2010)

17. A.Z. Mirza, F.A. Siddiqui, Nanomedicine and drug delivery: a mini review. Int. Nano Lett. 4, 94 (2014)

18. E. Miele, G.P. Spinelli, E. Miele, E. Di Fabrizio, E. Ferretti, S. Tomao, A. Gulino, Nanoparticle-based delivery of small interfering RNA: challenges for cancer therapy. Int. J. Nanomed. 7, 3637 (2012)

19. Q. Quan, Y. Zhang, Lab-ona-Tip (LOT): where nanotechnology can revolutionize fibre optics. Nanobiomedicine 2(2008), 5-10 (2015)

20. S. Bamrungsap, Z. Zhao, T. Chen, L. Wang, C. Li, T. Fu, W. Tan, Nanotechnology in therapeutics a focus on nanoparticles as a drug delivery system. Nanomedicine 7, 1253-1271 (2012)

21. S.K. Sahoo, S. Parveen, J.J. Panda, The present and future of nanotechnology in human health care. Nanomed.: Nanotechnol. Biol. Med. 3, 20-31 (2007)

22. M. Sengani, A.M. Grumezescu, V.D. Rajeswari, Recent trends and methodologies in gold nanoparticle synthesis - a prospective review on drug delivery aspect. OpenNano 2, 37-46 (2017)

23. P.Y. Liyanage, S.D. Hettiarachchi, Y. Zhou, A. Ouhtit, E.S. Seven, C.Y. Oztan, Nanoparticle-mediated targeted drug delivery for breast cancer treatment. Biochim. Biophys. Acta Rev. Cancer 1871(2), 419-433 (2019)

24. M.Z. Ahmad, S. Akhter, G.K. Jain, M. Rahman, S.A. Pathan, F.J. Ahmad, Metallic nanoparticles: technology overview and drug delivery applications in oncology. Expert Opin. Drug Deliv. 7(8), 927-942 (2010)

25. A. Alalaiwe, The clinical pharmacokinetics impact of medical nanometals on drug delivery system. Nanomed. Nanotechnol. Biol. Med. 17, 47-61 (2019)

26. B. Isaacoff, K. Brown, Progress in top-down control of bottom-up assembly. Nano Lett. 17, 6508-6510 (2017)

27. T.V.M. Sreekanth, P.C. Nagajyothi, P. Muthuraman, G. Enkhtaivan, S.V.P. Vattikuti, C.O. Tettey, Ultra-sonication-assisted silver nanoparticles using Panax ginseng root extract and their anti-cancer and antiviral activities. J. Photochem. Photobiol. B Biol. 188, 6-11 (2018)

28. L.D. Rampino, F.F. Nord, Preparation of palladium and platinum synthetic high polymer catalysts and the relationship between particle size and rate of hydrogenation. J. Am. Chem. Soc. 63(10), 2745-2749 (1941)

29. K.R. Brown, D. Walter, M.J. Natan, Seeding of colloidal Au nanoparticle solutions. 2. Improved control of particle size and shape. Chem. Mater. 12(2), 306-313 (2000)

30. N.G. Bastus, J. Comenge, V. Puntes, Kinetically controlled seeded growth synthesis of citrate-stabilized gold nanoparticles of up to $200 \mathrm{~nm}$ : size focusing versus Ostwald ripening. Langmuir 27(17), 11098-11105 (2011)

31. J.A. Khan, R.A. Kudgus, A. Szabolcs, S. Dutta, E. Wang, S. Cao et al., Designing nanoconjugates to effectively target pancreatic cancer cells in vitro and in vivo. PLoS One 6(6), e20347 (2011)

32. L. Lu, X. An, Silver nanoparticles synthesis using $\mathrm{H} 2$ as reducing agent in toluene-supercritical $\mathrm{CO}_{2}$ microemulsion. J. Supercrit. Fluids 99, 29-37 (2015)

33. O.A. Yıldırım, C. Durucan, Synthesis of zinc oxide nanoparticles elaborated by microemulsion method. J. Alloys Compd. 506(2), 944-949 (2010)

34. M.I. Khalil, M.M. Al-Qunaibit, A.M. Al-Zahem, J.P. Labis, Synthesis and characterization of $\mathrm{ZnO}$ nanoparticles by thermal decomposition of a curcumin zinc complex. Arab. J. Chem. 6(6), 1178-1184 (2014)

35. S. Chin, E. Park, M. Kim, J. Jurng, Photocatalytic degradation of methylene blue with $\mathrm{TiO}_{2}$ nanoparticles prepared by a thermal decomposition process. Powder Technol. 201(2), 171-176 (2010) 
36. A. Abulizi, G.H. Yang, K. Okitsu, J.-J. Zhu, Synthesis of $\mathrm{MnO} 2$ nanoparticles from sonochemical reduction of $\mathrm{MnO} 4-$ in water under different $\mathrm{pH}$ conditions. Ultrason. Sonochem. 21(5), 16291634 (2014)

37. J. Zhu, S. Liu, O. Palchik, Y. Koltypin, A. Gedanken, Shapecontrolled synthesis of silver nanoparticles by pulse sonoelectrochemical methods. Langmuir 16(16), 6396-6399 (2000)

38. N.A. Dhas, C.P. Raj, A. Gedanken, Synthesis, characterization, and properties of metallic copper nanoparticles. Chem. Mater. 10(5), 1446-1452 (1998)

39. L. Lu, X. An, Silver nanoparticles synthesis using $\mathrm{H} 2$ as reducing agent in toluene-supercritical CO2 microemulsion. J. Supercrit. Fluids 99, 29-37 (2015)

40. S. Komarneni, H. Katsuki, Nanophase materials by a novel microwave-hydrothermal process. Pure Appl. Chem. 74(9), 1537-1543 (2002)

41. D. Sharma, S. Sharma, B.S. Kaith, J. Rajput, M. Kaur, Synthesis of $\mathrm{ZnO}$ nanoparticles using surfactant free in-air and microwave method. Appl. Surf. Sci. 257(22), 9661-9672 (2011)

42. S. Barcikowski, F. Devesa, K. Moldenhauer, Impact and structure of literature on nanoparticle generation by laser ablation in liquids. J. Nanopart Res. 11, 1883-1893 (2009)

43. J. Bell, Z. Chen, A. Olofinjana, Synthesis of amorphous carbon nitride using reactive ion beam sputtering deposition with grazing bombardment. Diam. Relat. Mater. 10, 2184-2189 (2001)

44. L. Tapaszto, G. Dobrik, P. Lambin, L.P. Biro, Tailoring the atomic structure of graphene nanoribbons by scanning tunneling microscope lithography. Nat. Nanotechnol. 3, 397-401 (2008)

45. T. Nissinen, T. Ikonen, M. Lama, J. Riikonen, V.P. Lehto, Improved production efficiency of mesoporous silicon nanoparticles by pulsed electrochemical etching. Powder Technol. 288, 360-365 (2016)

46. Y.M. Manawi, Ihsanullah, A. Samara, T. Al-Ansari, M.A. Atieh, A review of carbon nanomaterials' synthesis via the chemical vapor deposition (CVD) method. Materials 11, 822 (2018)

47. G. Yi, Z. Wu, M. Sayer, Preparation of $\mathrm{Pb}(\mathrm{Zr}, \mathrm{Ti})_{\mathrm{O}} 3$ thin films by sol gel processing: electrical, optical, and electro-optic properties. J. Appl. Phys. 64, 2717-2724 (1988)

48. S. Rana, P.T. Kalaichelvan, Ecotoxicity of nanoparticles. ISRN Toxicology, 574648 (2013)

49. P. Mohanpuria, N.K. Rana, S.K. Yadav, Biosynthesis of nanoparticles: technological concepts and future applications. J. Nanopart Resvol. 10, 507-517 (2008)

50. D.K. Tiwari, J. Behari, P. Sen, Time and dose-dependent antimicrobial potential of $\mathrm{Ag}$ nanoparticles synthesized by top-down approach. Curr. Sci. 95, 647-655 (2008)

51. N.A. Luechinger, R.N. Grass, E.K. Athanassiou, W.J. Stark, Bottom-up fabrication of metal/metal nanocomposites from nanoparticles of immiscible metals. Chem. Mater. 22, 155-160 (2010)

52. P. Singh, Y.J. Kim, D.C. Yang, A strategic approach for rapid synthesis of gold and silver nanoparticles by Panax ginseng leaves. Artif. Cells Nanomed. Biotechnol. 44, 1949-1957 (2016)

53. P. Singh, Y.J. Kim, C. Wang, R. Mathiyalagan, M. El-Agamy Farh, D.C. Yang, Biogenic silver and gold nanoparticles synthesized using red ginseng root extract, and their applications. Artif. Cells Nanomed. Biotechnol. 44, 811-816 (2016)

54. M.K. Swamy, U.R. Sinniah, Patchouli (Pogostemon cablin Benth.): botany, grotechnology and biotechnological aspects. Ind. Crops Prod. 87, 161-176 (2016)

55. S.K. Mohanty, M.K. Swamy, U.R. Sinniah, M. Anuradha, Leptadenia reticulata (Retz.) Wight \& Arn. (Jivanti): botanical, agronomical, phytochemical, pharmacological, and biotechnological aspects. Molecules 22, 1019 (2017)

56. T. Rodrigues, D. Reker, P. Schneider, G. Schneider, Counting on natural products for drug design. Nat. Chem. 8, 531 (2016)
57. S.H. Thilakarathna, H. Rupasinghe, Flavonoid bioavailability and attempts for bioavailability enhancement. Nutrients $\mathbf{5}$, 3367-3387 (2013)

58. R. Watkins, L. Wu, C. Zhang, R.M. Davis, B. Xu, Natural product-based nanomedicine: recent advances and issues. Int. J. Nanomed. 10, 6055 (2015)

59. E.R. Cooper, Nanoparticles: a personal experience for formulating poorly water soluble drugs. J. Control. Release 141(3), 300-302 (2010)

60. K. Thanki, R.P. Gangwal, A.T. Sangamwar, S. Jain, Oral delivery of anticancer drugs: challenges and opportunities. J. Control Release 170(1), 15-40 (2013)

61. L. Gao, G. Liu, J. Ma, X. Wang, L. Zhou, X. Li, Drug nanocrystals: in vivo performances. J. Control Release 160(3), 418-430 (2012)

62. T.M. Allen, P.R. Cullis, Drug delivery systems: entering the mainstream. Science 303(5665), 1818-1822 (2004)

63. R. Gref, Y. Minamitake, M.T. Peracchia, V. Trubetskoy, V. Torchilin, R. Langer, Biodegradable long-circulating polymeric nanospheres. Science 263(5153), 1600-1603 (1994)

64. D. Mandal, A. Maran, M.J. Yaszemski, M.E. Bolander, G. Sarkar, Cellular uptake of gold nanoparticles directly crosslinked with carrier peptides by osteosarcoma cells. J. Mater. Sci. Mater. Med. 20(1), 347-350 (2009)

65. G. Tan, M.A. Onur, N. Sagam, Utilization of gold nanostructures in biomedical applications. Turk. J. Biol. 36(6), 607-621 (2012)

66. R. Langer, Drug delivery and targeting. Nature 392(Suppl. 6679), 5-10 (1998)

67. D. Delcassian, A.K. Patel, A.B. Cortinas, R. Langer, Drug delivery across length scales. J. Drug Target. 29(3), 229-243 (2019)

68. T.C. Yih, M. Al-Fandi, Engineered nanoparticles as precise drug delivery systems. J. Cell. Biochem. 97(6), 1184-1190 (2006)

69. S. Bhattacharyya, R.A. Kudgus, R. Bhattacharya, P. Mukherjee, Inorganic nanoparticles in cancer therapy. Pharm. Res. 28(2), 237-259 (2011)

70. N. Nishiyama, Nanomedicine: nanocarriers shape up for long life. Nat. Nanotechnol. 2(4), 203-204 (2007)

71. J. Conde, G. Doria, P. Baptista, Noble metal nanoparticles applications in cancer. J. Drug Deliv. 2012, 751075 (2012)

72. J. Xie, S. Lee, X. Chen, Nanoparticle-based theranostic agents. Adv. Drug Deliv. Rev. 62(11), 1064-1079 (2010)

73. T.K. Sau, A.L. Rogach, F. Jackel, T.A. Klar, J. Feldmann, Properties and applications of colloidal non spherical noble metal nanoparticles. Adv. Mater. 22, 1805-1825 (2010)

74. R.A. Sperling, P.R. Gil, F. Zhang, M. Zanella, W.J. Parak, Biological applications of gold nanoparticles. Chem. Soc. Rev. 37, 1896-1908 (2008)

75. P.K. Jain, X. Huang, I.H. El-Sayed, M.A. El-Sayed, Noble metals on the nanoscale: optical and photothermal properties and some applications in imaging, sensing, biology and medicine. Acc. Chem. Res. 41, 1578-1586 (2008)

76. K.S. Lee, M.A. El-Sayed, Gold and silver nanoparticles in sensing and imaging: sensitivity of plasmon response to size, shape, and metal composition. J. Phys. Chem. B 110, 19220-19225 (2006)

77. C.P. Schmitt, A.C. Genix, J.G. Alauzun, M. Sztucki, J. Oberdisse, P.H. Mutin, Surface modification of alumina-coated silica nanoparticles in aqueous sols with phosphonic acids and impact on nanoparticle interactions. Phys. Chem. Chem. Phys. 17, 19173$19182(2015)$

78. M. Vert, Y. Doi, K.H. Hellwich, M. Hess, P. Hodge, P. Kubisa, M. Rinaudo, F. Schue, Terminology for biorelated polymers and applications (IUPAC recommendations 2012). Pure Appl. Chem. 84, 377-410 (2012)
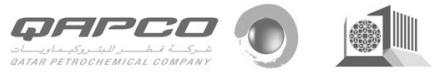
79. E. Arzt, Size effects in materials due to microstructural and dimensional constraints: a comparative review. Acta Mater. 46, 5611-5626 (1998)

80. G.R. Patzke, Y. Zhou, R. Kontic, F. Conrad, Oxide nanomaterials: synthetic developments, mechanistic studies, and technological innovations. Angew. Chem. Int. Ed. 50, 826-859 (2011)

81. J.A. Rodriguez, M. Fernandez-Garcia, Synthesis, properties, and applications of oxide nanomaterials (Wiley, Hoboken, 2007)

82. S. Jung Soo, X. Qingguo, K. Namho, H. Justin, E.M. Laura, PEGylation as a strategy for improving nanoparticle-based drug and gene delivery. Adv. Drug Deliv. Rev. 99, 28-51 (2016)

83. J.H. Clark, D.J. Macquarrie, Handbook of green chemistry and technology (Wiley, Hoboken, 2008)

84. K.C. Bhainsa, S.F. DSouza, Extracellular biosynthesis of silver nanoparticles using the fungus Aspergillus fumigatus. Colloids Surf B: Biointerfaces 47, 160-174 (2006)

85. A.R. Shahverdi, A. Fakhimi, H.R. Shahverdi, S. Minaian, Synthesis and effect of silver nanoparticles on the antibacterial activity of different antibiotics against Staphylococcus aureus and Escherichia coli. Nanomedicine 3, 168-171 (2007)

86. V.V. Makarov, A.J. Love, O.V. Sinitsyna, S.S. Makarova, I.V. Yaminsky, M.E. Taliansky, N.O. Kalinina, Green nanotechnologies: synthesis of metal nanoparticles using plants. Acta Nat. 6, 35-44 (2014)

87. S.K. Ritter, EPA analysis suggests green success. Chem. Eng. News. 93, 32-43 (2015)

88. M. Nasrollahzadeh, Z. Issaabadi, S.M. Sajadi, Green synthesis of a $\mathrm{Cu} / \mathrm{MgO}$ nanocomposite by Cassytha filiformis L. extract and investigation of its catalytic activity in the reduction of methylene blue, congo red and nitro compounds in aqueous media. RSC Adv. 8, 3723-3735 (2018)

89. P. Singh, Y.J. Kim, D. Zhang, D.C. Yang, Trends Biotechnol Biological synthesis of nanoparticles from plants and microorganisms. Trends Biotechnol. 34, 588-599 (2016)

90. D.J. Garole, B.C. Choudhary, D. Paul, A.U. Borse, Sorption and recovery of platinum from simulated spent catalyst solution and refinery wastewater using chemically modified biomass as a novel sorbent. Environ. Sci. Pollut. Res. 25, 10911-10925 (2018)

91. X. Fang, Y. Wang, Z. Wang, Z. Jiang, M. Dong, Microorganism assisted synthesized nanoparticles for catalytic applications. Energies 12, 190 (2019)

92. B. Buszewski, V. Railean-Plugaru, P. Pomastowski, K. Rafińska, M. Szultka-Mlynska, P. Golinska, M. Wypij, D. Laskowski, H. Dahm, Antimicrobial activity of biosilver nanoparticles produced by a novel Streptacidiphilus durhamensis strain. J. Microbiol. Immunol. Infect. 51, 45-54 (2018)

93. L. Gan, S. Zhang, Y. Zhang, S. He, Y. Tian, Biosynthesis, characterization and antimicrobial activity of silver nanoparticles by a halotolerant Bacillus endophyticus SCU-L. Prep. Biochem. Biotechnol. 48, 582-588 (2018)

94. J. Li, B. Tian, T. Li, S. Dai, Y. Weng, J. Lu, X. Xu, Y. Jin, R. Pang, Y. Hua, Biosynthesis of $\mathrm{Au}, \mathrm{Ag}$ and $\mathrm{Au}-\mathrm{Ag}$ bimetallic nanoparticles using protein extracts of Deinococcus radiodurans and evaluation of their cytotoxicity. Int. J. Nanomed. 13, 1411 (2018)

95. T. Klaus-Joerger, R. Joerger, E. Olsson, C.-G. Granqvist, Bacteria as workers in the living factory: metal-accumulating bacteria and their potential for materials science. Trends Biotechnol. 19, 15-20 (2001)

96. S.K. Srivastava, M. Constanti, Room temperature biogenic synthesis of multiple nanoparticles ( $\mathrm{Ag}, \mathrm{Pd}, \mathrm{Fe}, \mathrm{Rh}, \mathrm{Ni}, \mathrm{Ru}, \mathrm{Pt} \mathrm{Co}$, and $\mathrm{Li}$ ) by Pseudomonas aeruginosa SM1. J. Nanopart. Res. 14, 831 (2012)

97. E. Ahmed, S. Kalathil, L. Shi, O. Alharbi, P. Wang, Synthesis of ultra-small platinum, palladium and gold nanoparticles by Shewanella loihica PV-4 electrochemically active biofilms and their enhanced catalytic activities. J. Saudi Chem. Soc. 22, 919-929 (2018)

98. B. Srinath, K. Namratha, K. Byrappa, Eco-friendly synthesis of gold nanoparticles by Bacillus subtilis and their environmental applications. Adv. Sci. Lett. 24, 5942-5946 (2018)

99. L. Sintubin, W. De Windt, J. Dick, J. Mast, D. van der Ha, W. Verstraete, N. Boon, Lactic acid bacteria as reducing and capping agent for the fast and efficient production of silver nanoparticles. Appl. Microbiol. Biotechnol. 84, 741-749 (2009)

100. M. Manimaran, K. Kannabiran, Lett. Appl. Microbiol. 64, 40-408 (2017)

101. S. Otari, R. Patil, N. Nadaf, S. Ghosh, S. Pawar, Green biosynthesis of silver nanoparticles from an actinobacteria Rhodococcus sp. Mater. Lett 72, 92-94 (2012)

102. V. Buszewski, P. Railean-Plugaru, P. Pomastowski, K. Rafinska, M. Szultka-Mlynska, P. Golinska, M. Wypij, D. Laskowski, H. Dahm, Antimicrobial activity of biosilver nanoparticles produced by a novel Streptacidiphilus durhamensis strain. J. Microbiol. Immunol. Infect. 20, 1-10 (2016)

103. V. Ranjitha, V.R. Rai, Actinomycetes mediated synthesis of gold nanoparticles from the culture supernatant of Streptomyces griseoruber with special reference to catalytic activity. Biotech 7, 299 (2017)

104. S.E. Hassan, S.S. Salem, A. Fouda, M.A. Awad, M.S. ElGamal, A.M. Abdo, New approach for antimicrobial activity and bio-control of various pathogens by biosynthesized copper nanoparticles using endophytic actinomycetes. J. Radiat. Res. Appl. Sci. 30, 1-9 (2018)

105. P. Singh, Y.J. Kim, D. Zhang, D.C. Yang, Biological synthesis of nanoparticles from plants and microorganisms. Trends Biotechnol. 34, 588-599 (2016)

106. R.P. Metuku, S. Pabba, S. Burra, K. Gudikandula, M.S. Charya, Biosynthesis of silver nanoparticles from Schizophyllum radiatum HE 863742.1: their characterization and antimicrobial activity. Biotech 4, 227-234 (2014)

107. T. Ahmad, I.A. Wani, N. Manzoor, J. Ahmed, A.M. Asiri, Biosynthesis, structural characterization and antimicrobial activity of gold and silver nanoparticles. Colloids Surf. B 107, 227 (2013)

108. Y. Yin, X. Yang, L. Hu, Z. Tan, L. Zhao, Z. Zhang, J. Liu, G. Jiang, Superoxide-mediated extracellular biosynthesis of silver nanoparticles by the fungus Fusarium oxysporum. Environ. Sci. Technol. Lett. 3, 160-165 (2016)

109. M. Kitching, P. Choudhary, S. Inguva, Y. Guo, M. Ramani, S.K. Das, E. Marsili, Fungal surface protein mediated one-pot synthesis of stable and hemocompatible gold nanoparticles. Enzyme Microb. Technol. 95, 76-84 (2016)

110. M. Shah, D. Fawcett, S. Sharma, S. Tripathy, G. Poinern, Green synthesis of metallic nanoparticles via biological entities. Materials. 8, 7278-7308 (2015)

111. S.R. Waghmare, M.N. Mulla, S.R. Marathe, K.D. Sonawane, Ecofriendly production of silver nanoparticles using Candida utilis and its mechanistic action against pathogenic microorganisms. Biotech. 5, 33-38 (2015)

112. M. Eugenio, N. Muller, S. Frases, R. Almeida-Paes, L.M.T. Lima, L. Lemgruber, M. Farina, W. de Souza, C. SantAnna, Yeast-derived biosynthesis of silver/silver chloride nanoparticles and their antiproliferative activity against bacteria. RSC Adv. 6, 9893-9904 (2016)

113. J. Cao, R.H. Guenther, T.L. Sit, C.H. Opperman, S.A. Lommel, J.A. Willoughby, Loading and release mechanism of red clover necrotic mosaic virus derived plant viral nanoparticles for drug delivery of doxorubicin. Small 10, 5126-5136 (2014)

114. D.H. Le, K.L. Lee, S. Shukla, U. Commandeur, N.F. Steinmetz, Potato virus X, a filamentous plant viral nanoparticle for doxorubicin delivery in cancer therapy. Nanoscale 9, 2348-2357 (2017) 
115. A. Chauhan, S. Zubair, S. Tufail, A. Sherwani, M. Sajid, S.C. Raman, A. Azam, M. Owais, Fungus-mediated biological synthesis of gold nanoparticles: potential in detection of liver cancer. Int. J. Nanomed. 6, 2305 (2011)

116. T. Ahmad, I.A. Wani, N. Manzoor, J. Ahmed, A.M. Asiri, Biosynthesis, structural characterization and antimicrobial activity of gold and silver nanoparticles. Colloids Surf. B 107, 227 (2013)

117. K.B.D. Abhilash, Pandey, Microbial synthesis of iron-based nanomaterials-a review. Bull. Mater. Sci. 34, 191-198 (2011)

118. A. Ahmad, P. Mukherjee, D. Mandal, S. Senapati, M.I. Khan, R. Kumar, M. Sastry, Enzyme mediated extracellular synthesis of CdS nanoparticles by the fungus, Fusarium oxysporum. J. Am. Chem. Soc. 124, 12108-12119 (2002)

119. V. Bansal, D. Rautaray, A. Ahmada, M. Sastry, Biosynthesis of zirconiananoparticles using the fungus Fusarium oxysporum. J. Mater. Chem. 14, 3303-3305 (2004)

120. S. He, Z. Guo, Y. Zhang, S. Zhang, J. Wang, N. Gu, Biosynthesis of gold nanoparticles using the bacteria Rhodopseudomonas capsulate. Mater. Lett. 61, 3984 (2007)

121. D. Venkataraman, K. Kalimuthu, R.K.P. Sureshbabu, G. Sangiliyandi, Metal Nanoparticles in Microbiology, ed. M. Rai and N. Duran, Springer, XI 17-35 (2011)

122. P. Kuppusamy, M.M. Yusoff, G.P. Maniam, N. Govindan, Biosynthesis of metallic nanoparticles using plant derivatives and their new avenues in pharmacological applications-an updated report. Saudi Pharm. J. 24, 473 (2016)

123. S. Iravani, Green synthesis of metal nanoparticles using plants. Green Chem. 13, 2638 (2011)

124. O.V. Kharissova, H.V.R. Dias, B.I. Kharisov, B.O. Perez, M. Victor, J. Perez, The greener synthesis of nanoparticles. Trends Biotechnol. 31, 240 (2013)

125. V.V. Makarov, A.J. Love, O.V. Sinitsyna, S.S. Makarova, I.V. Yaminsky, M.E. Taliansky, N.O. Kalinina, "Green" nanotechnologies: synthesis of metal nanoparticles using plants. Acta Nat. 6, 35-44 (2014)

126. R. Sankar, P. Manikandan, V. Malarvizhi, T. Fathima, K.S. Shivashangari, V. Ravikumar, Spectrochim. Acta Part A. 121, 746-750 (2014)

127. M. El-Kemary, M. Zahran, S.A.M. Khalifa, H.R. El-Seedi, Spectral characterisation of the silver nanoparticles biosynthesised using Ambrosia maritima plant. Micro Nano Lett. 11, $311(2016)$

128. S. Li, Y. Shen, A. Xie, X. Yu, X. Zhang, L. Yang, C. Li, Rapid, room-temperature synthesis of amorphous selenium/protein composites using Capsicum annuum L extract. Nanotechnol. Nanotechnol 18, 405101 (2007)

129. C.G. Kumar, S.K. Mamidyala, Extracellular synthesis of silver nanoparticles using culture supernatant of Pseudomonas aeruginosa. Colloids Surf. B 84, 462-466 (2011)

130. S.K. Srikar, D.D. Giri, D.B. Pal, P. Mishra, S. Upadhyay, Light induced green synthesis of silver nanoparticles using aqueous extract of Prunus amygdalus. Green Sustain. Chem. 6, 26 (2016)

131. P.R. Selvakannan, A. Swami, D. Srisathiyanarayanan, P.S. Shirude, R. Pasricha, A.B. Mandale, M. Sastry, Synthesis of aqueous Au core- Ag shell nanoparticles using tyrosine as a $\mathrm{pH}$-dependent reducing agent and assembling phase-transferred silver nanoparticles at the air-water interface. Langmuir 20, 7825 (2004)

132. S.N. Sinha, D. Paul, Phytosynthesis of silver nanoparticles using andrographis paniculata leaf extract and evaluation of their antibacterial activities. Spectrosc. Lett. 48, 600 (2015)

133. R. Tamileswari, M. Haniff Nisha, S.S. Jesurani, Green synthesis of silver nanoparticles using Brassica oleracea (cauliflower) and Brassica oleracea Capitata (cabbage) and the analysis of antimicrobial activity. Int. J. Eng. Res. Technol. 4, 1071 (2015)
134. M. Zahran, M. El-Kemary, S. Khalifa, H. El-Seedi, Spectral studies of silver nanoparticles biosynthesized by Origanum majorana. Green Process. Synth. 7, 100-105 (2018)

135. K. Tahir, S. Nazir, B. Li, A. Ahmad, T. Nasir, A.U. Khan, S.A.A. Shah, Z.U.H. Khan, G. Yasin, M.U. Hameed, Sapium sebiferum leaf extract mediated synthesis of palladium nanoparticles and in vitro investigation of their bacterial and photocatalytic activities. J. Photochem. Photobiol. B. 164, 164-173 (2016)

136. S.J. Lakshmi, R.R. Bai, H. Sharanagouda, C.T. Ramachandra, S. Nadagouda, S.R. Doddagoudar, Biosynthesis and characterization of $\mathrm{ZnO}$ nanoparticles from spinach (Spinacia oleracea) leaves and its effect on seed quality parameters of greengram (Vigna radiata). Int. J. Curr. Microbiol. Appl. Sci. 6, 3376-3384 (2017)

137. R.W. Raut, V.D. Mendhulkar, S.B. Kashid, Synthesis of silver nanoparticles using Withania somnifera leaf powder and silver nitrate. J. Photochem. Photobiol. B. 132, 45 (2014)

138. R.R. Fouad, H.A. Aljohani, K.R. Shoueir, Biocompatible poly(vinyl alcohol) nanoparticle-based binary blends for oil spill control. Mar. Pollut. Bull. 112, 46 (2016)

139. D. Mott, J. Galkowski, L. Wang, J. Luo, C.J. Zhong, Synthesis of size-controlled and shaped copper nanoparticles. Langmuir 23, 5740 (2007)

140. K. Punjabi, P. Choudhary, L. Samant, S. Mukhejee, S. Vaidya, A. Chowdhary, Biosynthesis of nanoparticles: a review. Int. J. Pharm. Sci. Rev. Res. 30, 219 (2015)

141. M. Darroudi, M.B. Ahmad, R. Zamiri, A.K. Zak, A.H. Abdullah, N.A. Ibrahim, Time-dependent effect in green synthesis of silver nanoparticles. Int. J. Nanomed. 6, 677 (2011)

142. V. Gopinath, S. Priyadarshini, M.F. Loke, J. Arunkumar, E. Marsili, D. Mubarak Ali, P. Velusamy, J. Vadivelu, Biogenic synthesis, characterization of antibacterial silver nanoparticles and its cell cytotoxicity. Arab. J. Chem. 10, 1107-1117 (2017)

143. J. Suksaeree, A. Thuengernthong, K. Pongpichayasiri, P. Maneewattanapinyo, S. Settharaksa, W. Pichayakorn, Formulation and evaluation of matrix type transdermal patch containing silver nanoparticles. J. Polym. Environ. 26, 4369-4375 (2018)

144. M. Sharma, Transdermal and intravenous nano drug delivery systems, applications of targeted nano drugs and delivery systems, Elsevier Inc.; 499-550 (2019)

145. B. Le, O.F. Stellacci, Antibacterial activity of silver nanoparticles: a surface science insight. Nano Today. 10, 339-354 (2015)

146. A. Jemal, R. Siegel, J. Xu, E. Ward, Cancer statistics. CA Cancer J. Clin. 60, 277-300 (2010)

147. A. Balmain, J. Gray, B. Ponder, The genetics and genomics of cancer. Nat. Genet. 33, 238-244 (2003)

148. S.C. Sahu, J. Zheng, L. Graham, L. Chen, J. Ihrie, J.J. Yourick, R.L. Sprando, Comparative cytotoxicity of nanosilver in human liver HepG2 and colon Caco 2 cells in culture. J. Appl. Toxicol. 34, 1155-1166 (2014)

149. N.M. El-Deeb, I.M. El-Sherbiny, M.R. El-Aassara, E.E. Hafez, Novel trend in colon cancer therapy using silver nanoparticles synthesized by honey bee. J. Nanomed. Nanotechnol. 6, 265 (2015)

150. I.M. Chung, I. Park, K. Seung-Hyun, M. Thiruvengadam, G. Rajakumar, Plant-mediated synthesis of silver nanoparticles: their characteristic properties and therapeutic applications. Nanoscale Res. Lett. 11, 40 (2016)

151. Y. He, Z. Du, S. Ma, Y. Liu, D. Li, H. Huang, S. Jiang, S. Cheng, W. Wu, K. Zhang, Effects of green-synthesized silver nanoparticles on lung cancer cells in vitro and grown as xenograft tumors in vivo. Int. J. Nanomed. 11, 1879 (2016)

152. S. Gurunathan, M. Qasim, C. Park, H. Yoo, J.H. Kim, K. Hong, Cytotoxic potential and molecular pathway analysis of silver nanoparticles in human colon cancer cells HCT116. Int. J. Mol. Sci. 19, 2269 (2018)

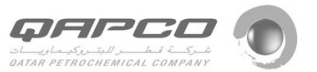


153. L. Bohmert, B. Niemann, D. Lichtenstein, S. Juling, A. Lampen, Molecular mechanism of silver nanoparticles in human intestinal cells. Nanotoxicology 9, 852-860 (2015)

154. S. Mani, M.G. Balasubramanian, P. Ponnusamy, P. Vijayan, Antineoplastic effect of PAC capped silver nanoparticles promote apoptosis in HT-29 human colon cancer cells. J. Clust. Sci. 30, 483-493 (2019)

155. H. Chugh, D. Sood, I. Chandra, V. Tomar, G. Dhawan, R. Chandra, Role of gold and silver nanoparticles in cancer nano-medicine. Artif. Cells Nanomed. Biotechnol. 46, 1210-1220 (2018)

156. P. Mathur, S. Jha, S. Ramteke, N. Jain, Pharmaceutical aspects of silver nanoparticles. Artif. Cells Nanomed. Biotechnol. 46, $115-126$ (2018)

157. Y.H. Hsin, C.F. Chen, S. Huang, T.S. Shih, P.S. Lai, P.J. Chueh, The apoptotic effect of nanosilver is mediated by a ROS-and JNK-dependent mechanism involving the mitochondrial pathway in NIH3T3 cells. Toxicol. Lett. 179, 130-139 (2008)

158. K.X. Lee, K. Shameli, S.E. Mohamad, Y.P. Yew, E.D.M. Isa, H.Y. Yap, W.L. Lim, S.Y. Teow, Bio-mediated synthesis and characterisation of silver nanocarrier, and its potent anticancer action. Nanomaterials 9, 1-19 (2019)

159. M. Rozalen, M. Sánchez-Polo, M. Fernandez-Perales, T.J. Widmann, J. Rivera-Utrilla, Synthesis of controlled-size silver nanoparticles for the administration of methotrexate drug and its activity in colon and lung cancer cells. RSC Adv. 10, 10646$10660(2020)$

160. R.K. Thapa, J.H. Kim, J.H. Jeong, B.S. Shin, H.G. Choi, C.S. Yong, J.O. Kim, Silver nanoparticle-embedded grapheme oxidemethotrexate for targeted cancer treatment. Colloids Surf. B Biointerfaces 153, 95-103 (2017)

161. P.K. Palai, A. Mondal, C.K. Chakraborti, I. Banerjee, K. Pal, Green synthesized amino-PEGylated silver decorated grapheme nanoplatform as a tumor-targeted controlled drug delivery system. SN Appl. Sci. 1, 269 (2019)

162. F. Zeng, D. Xu, C. Zhan, C. Liang, W. Zhao, J. Zhang, H. Feng, $X$. Ma, Surfactant-free synthesis of graphene oxide coated silver nanoparticles for SERS biosensing and intracellular drug delivery. ACS Appl. Nano Mater. 1, 2748-2753 (2018)

163. S. Patra, S. Mukherjee, A.K. Barui, A. Ganguly, B. Sreedhar, C.R. Patra, Green synthesis, characterization of gold and silver nanoparticles and their potential application for cancer therapeutics. Mater. Sci. Eng. C Mater. Biol. Appl. 53, 298-309 (2015)

164. S.A.S. Shandiz, M.S. Ardestani, D. Shahbazzadeh, A. Assadi, R.A. Cohan, V. Asgary, S. Salehi, Novel imatinib-loaded silver nanoparticles for enhanced apoptosis of human breast cancer MCF-7 cells. Artif. Cells Nanomed. Biotechnol. 45, 1-10 (2017)

165. Y.G. Yuan, Q.L. Peng, S. Gurunathan, Silver nanoparticles enhance the apoptotic potential of gemcitabine in human ovarian cancer cells: combination therapy for effective cancer treatment. Int. J. Nanomed. 12, 6487-6502 (2017)

166. S. Gurunathan, M. Qasim, Y. Choi, J. Tae Do, C. Park, K. Hong, J.H. Kim, H. Song, Antiviral potential of nanoparticles-can nanoparticles fight against coronaviruses? Nanomaterials 10, 1645 (2020)

167. Y.G. Yuan, S. Zhang, J.Y. Hwang, I.K. Kong, Silver nanoparticles potentiates cytotoxicity and apoptotic potential of camptothecin in human cervical cancer cells. Oxid. Med. Cell Longev. 6121328 (2018)

168. Y. Li, Z. Lin, M. Zhao, M. Guo, T. Xu, C. Wang, H. Xia, B. Zhu, Reversal of H1N1 influenza virus-induced apoptosis by silver nanoparticles functionalized with amantadine. RSC Adv. 6, 89679-89686 (2016)

169. S. Jain, D.G. Hirst, J.M. O'Sullivan, Gold nanoparticles as novel agents for cancer therapy. Br. J. Radiol. 85, 101-113 (2012)

170. E.K. Chow, D. Ho, Cancer nanomedicine: from drug delivery to imaging. Sci. Transl. Med. 5, 216rv4 (2013)
171. A. Alkilany, C. Murphy, Toxicity and cellular uptake of gold nanoparticles: what we have learned so far? J. Nanopart. Res. 12, 2313-2333 (2010)

172. C. Tiloke, A. Phulukdaree, K. Anand, R.M. Gengan, A.A. Chuturgoon, Moringa oleifera gold nanoparticles modulate oncogenes, tumor suppressor genes, and caspase-9 splice variants in A549 cells. J. Cell Biochem. 117, 2302-2314 (2016)

173. W. Cui, J. Li, Y. Zhang, H. Rong, W. Lu, L. Jiang, Effects of aggregation and the surface properties of gold nanoparticles on cytotoxicity and cell growth. Nanomedicine: NBM 8, 46-53 (2012)

174. Y. Pan, S. Neuss, A. Leifert, M. Fischler, F. Wen, U. Simon, G. Schmid, W. Brandau, W. Jahnen-Dechent, Size-dependent cytotoxicity of gold nanoparticles. Small 3, 1941-1949 (2007)

175. N. Gong, S. Chen, S. Jin, J. Zhang, P.C. Wang, X.J. Liang, Effect of the physicochemical properties of gold nanostructures on cellular internalization. Regen. Biomater. 2, 273-280 (2015)

176. A. Albanese, P.S. Tang, W.C.W. Chan, The effect of nanoparticle size, shape, and surface chemistry on biological systems. Annu. Rev. Biomed. Eng. 14, 1-16 (2012)

177. U.F. Muhammad, V. Novosad, A.E. Rozhkova, H. Wali, A. Ali, A.A. Fateh, P.B. Neogi, A. Neogi, Z. Wang, Gold nanoparticlesenabled efficient dual delivery of anticancer therapeutics to HeLa cells. Sci. Rep. 8, 2907 (2018)

178. C.R. Patra, R. Bhattacharya, D. Mukhopadhyay, P. Mukherjee, Fabrication of gold nanoparticles for targeted therapy in pancreatic cancer. Adv. Drug Deliv. Rev. 8, 346-361 (2010)

179. M. Eghtedari, A.V. Liopo, J.A. Copland, A.A. Oraevsky, M. Motamed, Engineering of hetero-functional gold nanorods for the in vivo molecular targeting of breast cancer cells. Nano Lett. 9, 287-291 (2009)

180. Z. Golkar, O. Bagazra, D.G. Pace, Bacteriophage therapy: a potential solution for the antibiotic resistance crisis. J. Infect. Dev. Ctries. 8, 129-136 (2014)

181. I.M. Gould, A.M. Bal, New antibiotic agents in the pipeline and how they can overcome microbial resistance. Virulence 4, 185-191 (2013)

182. C. Su, K. Huang, L. Hao-Hong, L. You-Guang, Z. Da-Li, Antibacterial properties of functionalized gold nanoparticles and their application in oral biology. J. Nanomater. 5616379 (2020)

183. A.N. Brown, K. Smith, T.A. Samuels, J. Lu, S.O. Obare, M.E. Scott, Nanoparticles functionalized with ampicillin destroy multiple-antibiotic-resistant isolates of Pseudomonas aeruginosa and Enterobacter aerogenes and methicillin-resistant Staphylococcus aureus. Appl. Environ. Microbiol. 78, 2768-2774 (2012)

184. K. Govindaraju, K.S.U. Suganya, In vitro anti-diabetic assessment of guavanoic acid functionalized gold nanoparticles in regulating glucose transport using L6 rat skeletal muscle cells. RSC Med. Chem. 11, 814-822 (2020)

185. Y. Zhang, M. Wu, D. Tan, Q. Liu, R. Xia, M. Chen, Y. Liu, L. Xue, Y. Lei, A dissolving and glucose-responsive insulinreleasing microneedle patch for type 1 diabetes therapy. J. Mater. Chem. B 9, 648-657 (2021)

186. Y. Zhang, M. Wu, W. Dai, Y. Li, X. Wang, D. Tan, Z. Yang, S. Liu, L. Xue, Y. Lei, Gold nanoclusters for controlled insulin release and glucose regulation in diabetes. Nanoscale 11, 64716479 (2019)

187. H. Agarwal, A. Nakara, V.K. Shanmugam, Anti-inflammatory mechanism of various metal and metal oxide nanoparticles synthesized using plant extracts: a review. Biomed. Pharmacother. 109, 2561-2572 (2019)

188. H.J. Kim, S.M. Lee, K.H. Park, C.H. Mun, Y.B. Park, K.H. Yoo, Drug-loaded gold/iron/gold plasmonic nanoparticles for magnetic targeted chemo-photothermal treatment of rheumatoid arthritis. Biomaterials 61, 95-102 (2015) 
189. S.B. Yaqoob, R. Adnan, R.M.R. Khan, M. Rashid, Gold, silver, and palladium nanoparticles: a chemical tool for biomedical applications. Front. Chem. 8, 376 (2020)

190. V. Leso, I. Iavicoli, Palladium nanoparticles: toxicological effects and potential implications for occupational risk assessment. Int. J. Mol. Sci. 19, 503 (2018)

191. K. Shanthi, K. Vimala, D. Gopi, S. Kannan, Fabrication of a pH responsive DOXconjugated PEGylated palladium nanoparticle mediated drug delivery system: an in vitro and in vivo evaluation. RSC Adv. 5, 44998-45014 (2015)

192. T.C. Johnstone, K. Suntharalingam, S.J. Lippard, The next generation of platinum drugs: targeted $\mathrm{Pt}(\mathrm{II})$ agents, nanoparticle delivery and Pt (IV) prodrugs. Chem. Rev. 116, 3436-3486 (2016)

193. Z. Wang, L. Chen, C. Huang, Y. Huang, N. Jia, Albuminmediated platinum nanocrystals for in vivo enhanced computed tomography imaging. J. Mater. Chem. B. 5, 3498-3510 (2017)

194. R.E. Doherty, I.V. Sazanovich, L.K. McKenzie, A.S. Stasheuski, R. Coyle, E. Baggaley, S. Bottomley, J.A. Weinstein, H.E. Bryant, Photodynamic killing of cancer cells by a platinum(II) complex with cyclometallating ligand. Sci. Rep. 6, 22668 (2016)

195. S. Mukherjee, R. Kotcherlakota, S. Haqueac, D. Bhattacharyaa, J. Mahesh Kumar, S. Chakravarty, C.R. Patraac, Improved delivery of doxorubicin using rationally designed PEGylated platinum nanoparticles for the treatment of melanoma. Mater. Sci. Eng. C 108, 110375 (2020)

196. M.B. Gawande, A. Goswami, F.X. Felpin, T. Asefa, X. Huang, R. Silva, X. Zou, R. Zboril, S. Rajender, S. Varma, $\mathrm{Cu}$ and $\mathrm{Cu}$-based nanoparticles: synthesis and applications in catalysis. Chem. Rev. 116, 3722-3811 (2016)

197. B.C. Ranu, R. Dey, T. Chatterjee, S. Ahammed, Copper nanoparticle-catalyzed carbon-carbon and carbon-heteroatom bond formation with a greener perspective. Chemsuschem 5, 22-44 (2012)

198. Y. Ahn, Y. Jeong, D. Lee, Y. Lee, Copper nanowire-graphene core-shell nanostructure for highly stable transparent conducting electrodes. ACS Nano 9, 3125-3133 (2015)

199. S. Bhanushali, P. Ghosh, A. Ganesh, W. Cheng, 1D copper nanostructures: progress, challenges and opportunities. Small. 11, 1232-1252 (2015)

200. U. Goswami, A. Dutta, A. Raza, R. Kandimalla, S. Kalita, S. Sankar Ghosh, A. Chattopadhyay, Transferrin-copper nanocluster-doxorubicin nanoparticles as targeted theranostic cancer nanodrug. ACS Appl. Mater Interfaces 10, 3282-3294 (2018)

201. S. Kamble, B. Utage, P. Mogle, R. Kamble, S. Hese, B. Dawane, R. Gacche, Evaluation of curcumin capped copper nanoparticles as possible inhibitors of human breast cancer cells and angiogenesis: a comparative study with native curcumin. AAPS PharmSciTech 17, 1030-1041 (2016)

202. V. Verma, D. Kaushik, Mupirocin Mounted copper nanoparticle offered augmented drug delivery against resistant bacteria. Indian J. Pharm. Educ. Res. 54, 637-646 (2020)

203. H. Zhang, B. Chen, H. Jiang, A strategy for ZnO nanorod mediated multi-mode cancer treatment. Biomaterials 32, 1906-1914 (2011)

204. J. Hussein, M.F. Attia, M. El, S.M. El-daly, N. Mohamed, Z. Elkhayat, M.E. El-naggar, Solid state synthesis of docosahexaenoic acid-loaded zinc oxide nanoparticles as a potential antidiabetic agent in rats. Int. J. Biol. Macromol. 140, 1305-1314 (2019)

205. P. Chauhan, S. Mahajan, G.B.K.S. Prasad, Preparation and characterization of CS-ZnO-NC nanoparticles for imparting antidiabetic activities in experimental diabetes. J. Drug Deliv. Sci. Technol. 52, 738-747 (2019)

206. E. Yadav, D. Singh, P. Yadav, A. Verma, Ameliorative effect of biofabricated $\mathrm{ZnO}$ nanoparticles of Trianthema portulacastrum Linn and inflammation. RSC Adv. 8, 21621-21635 (2018)
207. D. Ziental, B.C. Goslinska, D.T. Mlynarczyk, A.G. Sobotta, B. Stanisz, T. Goslinski, L. Sobotta, Titanium dioxide nanoparticles: prospects and applications in medicine. Nanomaterials $\mathbf{1 0}$, $387(2020)$

208. J. Xu, Y. Sun, J. Huang, C. Chen, G. Liu, Y. Jiang, Y. Zhao, Y. Jiang, Photokilling cancer cells using highly cell-specific antibody-TiO2 bioconjugates and electroporation. Bioelectrochemistry 71, 217-222 (2007)

209. W. Ni, M. Li, J. Cui, Z. Xing, Z. Li, X. Wu, E. Song, M. Gong, W. Zhou, $808 \mathrm{~nm}$ light triggered black TiO2 nanoparticles for killing of bladder cancer cells. Mater. Sci. Eng. C. 81, 252-260 (2017)

210. Y. Chen, Y. Wan, Y. Wang, H. Zhang, Z. Jiao, Anticancer efficacy enhancement and attenuation of side effects of doxorubicin with titanium dioxide nanoparticles. Int. J. Nanomed. 6, 2321-2326 (2011)

211. F.U. Rehman, M.A. Rauf, S. Ullah, S. Shaikh, A. Qambrani, P. Muhammad, S. Hanif, Ultrasound-activated nano-TiO2 loaded with temozolomide paves the way for resection of chemoresistant glioblastoma multiforme. Cancer Nanotechnol. 12, 17 (2021)

212. T. Lopez, J. Sotelo, J. Navarrete, J.A. Ascencio, Synthesis of $\mathrm{TiO} 2$ nanostructured reservoir with temozolomide: structural evolution of the occluded drug. Opt. Mater. 29, 88-94 (2006)

213. M. Uddin, D. Mondal, C.A. Morris, T. Lopez, U. Diebold, R.D. Gonzalez, An in vitro controlled release study of valproic acid encapsulated in a Titania ceramic matrix. App. Surf Sci. 257, 7920-7927 (2011)

214. P. Xu, R. Wang, J. Ouyang, B. Chen, A new strategy for TiO2 whiskers mediated multi-mode cancer treatment. Nanoscale Res. Let. 10, 1-11 (2015)

215. H. Zhang, C. Wang, B. Chen, X. Wang, Daunorubicin-TiO2 nanocomposites as a "smart" $\mathrm{pH}$-responsive drug delivery system. Int. J. Nanomed. 7, 235-242 (2012)

216. N. Li, Q. Sun, Z. Yu, X. Gao, W. Pan, X. Wan, B. Tang, Nucleartargeted photothermal therapy prevents cancer recurrence with near-infrared triggered copper sulfide nanoparticles. ACS Nano 12, 5197-5206 (2018)

217. X. Yi, L. Chen, J. Chen, D. Maiti, Z.F. Chai, Z. Liu, K. Yang, Biomimetic copper sulfide for chemo-radiotherapy: enhanced uptake and reduced efflux of nanoparticles for tumor cells under ionizing radiation. Adv. Func. Mater. 28, 11 (2018)

218. R. Yang, R. Li, L. Zhang, Z. Xu, Y. Kang, P. Xue, Facile synthesis of hollow mesoporous nickel sulphide nanoparticles for highly efficient combinatorial photothermal-chemotherapy of cancer. J. Mater. Chem. B 8, 7766 (2020)

219. Q. Li, L. Sun, M. Hou, Q. Chen, R. Yang, L. Zhang, Z. Xu, Y. Kang, P. Xue, Phase-change material packaged within hollow copper sulfide nanoparticles carrying doxorubicin and chlorine 6 for fluorescence-guided trimodal therapy of cancer. ACS Appl. Mater. Interfaces 11, 417-429 (2019)

220. L. Hou, X. Shan, L. Hao, Q. Feng, Z. Zhang, Copper sulfide nanoparticle-based localized drug delivery system as an effective cancer synergistic treatment and theranostic platform. Acta Biomater. 54, 307-320 (2017)

221. Z. Xie, D. Wang, T. Fan, C. Xing, Z. Li, W. Tao, L. Liu, S. Bao, D. Fana, H. Zhang, Black phosphorus analogue tin sulfide nanosheets: synthesis and application as near-infrared photothermal agents and drug delivery platforms for cancer therapy. J. Mater. Chem. B. 6, 4747 (2018)

222. Y. Sun, L. Zheng, Y. Yang, X. Qian, T. Fu, X. Li, Z. Yang, H. Yan, C. Cui, W. Tan, Metal-organic framework nanocarriers for drug delivery in biomedical applications. Nano-Micro Lett. 12, $103(2020)$

223. C.Y. Sun, C. Qin, X.L. Wang, Z.M. Su, Metal-organic frameworks as potential drug delivery systems. Expert Opin. Drug Deliv. 10, 89-101 (2013) 
224. M. Gimenez-Marques, T. Hidalgo, C. Serre, P. Horcajada, Nanostructured metal-organic frameworks and their bio-related applications. Coord. Chem. Rev. 307, 342-360 (2016)

225. B.A. Lakshmi, S. Kim, Current and emerging applications of nanostructured metal-organic frameworks in cancer-targeted theranostics. Mater. Sci. Eng. C 105, 110091 (2019)

226. H.L. Wang, H. Yeh, B.H. Li, C.H. Lin, T.C. Hsiao, D.H. Tsai, Zirconium-based metal-organic framework nanocarrier for the controlled release of ibuprofen. ACS Appl. Nano Mater. 2, 33293334 (2019)

227. P. Horcajada, T. Chalati, C. Serre, B. Gillet, C. Sebrie, T. Baati, J.F. Eubank, D. Heurtaux, P. Clayette, C. Kreuz, J.S. Chang, Y.K. Hwang, V. Marsaud, P.N. Bories, L. Cynober, S. Gil, G. Ferey, P.
Couvreur, R. Gref. Porous metal-organic-framework nanoscale carriers as a potential platform for drug delivery and imaging. Nature Materials 9, 172-178 (2010)

228. W.H. Chen, X. Yu, W.C. Liao, Y.S. Sohn, A. Cecconello, A. Kozell, R. Nechushtai, I. Willner, ATP-responsive aptamerbased metal-organic framework nanoparticles (NMOFs) for the controlled release of loads and drugs. Adv. Funct. Mater. 27, 1702102 (2017)

229. J. Zhuang, C.H. Kuo, L.Y. Chou, D.Y. Liu, E. Weerapana, C.K. Tsung, Optimized metal-organic-framework nanospheres for drug delivery: evaluation of small-molecule encapsulation. ACS Nano 8, 2812-2819 (2014) 